\title{
L'HOMME L'Homme
}

Revue française d'anthropologie

$193 \mid 2010$

Claude Lévi-Strauss (1908-2009)

\section{Parenté et alliance en Europe occidentale. Un essai d'interprétation générale}

Kinship And Alliance in Western Europe: A General Interpretation

\section{Gérard Delille}

\section{(2) OpenEdition}

\section{Journals}

Édition électronique

URL : http://journals.openedition.org/lhomme/24351

DOI : 10.4000//homme.24351

ISSN : 1953-8103

Éditeur

Éditions de l'EHESS

Édition imprimée

Date de publication : 19 février 2010

Pagination : 75-135

ISSN : 0439-4216

\section{Référence électronique}

Gérard Delille, «Parenté et alliance en Europe occidentale. Un essai d'interprétation générale »,

L'Homme [En ligne], 193 | 2010, mis en ligne le 29 janvier 2012, consulté le 30 avril 2019. URL : http:// journals.openedition.org/lhomme/24351; DOI : 10.4000/lhomme.24351 


\section{Parenté et alliance en Europe occidentale}

Un essai d'interprétation générale

\section{Gérard Delille}

D

ANS UN OUVRAGE IMPORTANT qui a marqué une génération d'historiens et d'anthropologues, The Development of the Family and Marriage in Europe, Jack Goody (1983) a tenté de dégager les caractéristiques essentielles du "système chrétien " de parenté et d'alliance qui se met en place à partir de la fin de l'Antiquité tardive. En Occident, ce système trouve, sous l'impulsion d'abord prudente puis de plus en plus vigoureuse - à partir surtout des VIII et $\mathrm{IX}^{\mathrm{e}}$ siècles - de l'Église, ses bases fondamentales et définitives au XII ${ }^{\mathrm{e}}-\mathrm{XIII}{ }^{\mathrm{e}}$ siècle avec les grands traités de Pierre Damien et de Gratien, puis avec le concile du Latran qui, en 1215, fixe les interdits de consanguinité et d'affinité au $4^{\mathrm{e}}$ degré canonique (ils ne seront modifiés qu'au début du XX $\mathrm{XX}^{\mathrm{e}}$ siècle), mais autorise aussi les redoublements d'alliances entre consanguins proches de même sexe ou de sexe différent. Ainsi, deux frères peuvent épouser deux sœurs d'une autre famille, un veuf et son fils peuvent épouser une veuve et sa fille... toutes alliances jusque-là théoriquement interdites depuis les décisions prises à Constantinople, en 691, par le concile in Trullo.

Ce système occidental est cognatique (la filiation passe aussi bien par les hommes que par les femmes; le vocabulaire de la parenté est de type eskimo et ne distingue pas, comme le faisait le latin archaïque, les collatéraux du côté masculin de ceux du côté féminin) et monogame. Le divorce et l'adoption sont interdits ou fortement réprouvés, ce qui fragilise les lignées. Il privilégie les mariages tardifs et les regroupements conjugaux réduits. Il est enfin caractérisé par une transmission divergente des biens (c'est-à-dire par les hommes comme par les femmes même si ces passages se déclinent sous des formes très différentes d'une région ou d'un groupe social à un autre) qui accentue fortement son caractère cognatique. 
Tout cela n'exclut pas, pour Jack Goody, la permanence de pratiques relevant d'une "économie cachée de la parenté" ("the hidden economy of kinship ", cf. ibid. : chap. VII) qui, selon les circonstances, tend à favoriser des unions consanguines et affines contraires aux lois canoniques, ou toutes autres formes de refus de l'exogamie imposée par l'Église. Cette "économie cachée» ne repose cependant sur aucune règle d'échange préférentielle ("the absence of any organising preferences", cf. ibid.: 31) et n'implique pas la présence de groupes échangistes. Dès lors, les alliances ne sont pas orientées et les notions de cycle et de bouclage sont étrangères au système. Pour Maurice Godelier qui partage ce point de vue, le principe de l'échange direct des femmes a disparu et «il n'y a pas de raisons, dans la parenté, pour que les alliances se bouclent sur elles-mêmes " (2004: 230). Beaucoup d'historiens et d'anthropologues en concluent que la parenté et l'alliance donnent la précédence à des motivations de type économique ou politique.

Dans son étude sur le pays bigouden, Martine Segalen (1985) propose une interprétation plus nuancée. Du milieu du XVIII et pendant tout le XIX siècle, les unions se nouent par le biais de "ré-enchaînements d'alliances ", c'est-à-dire par des relations dans l'affinité avec en commun deux paires d'ancêtres (par exemple, un frère et une sœur épousent une sœur et un frère d'une autre famille). Ces ré-enchaînements peuvent prendre des formes complexes et "passer par la collatéralité, par le remariage, et une succession de relations d'affinités et de consanguinités" (ibid. : 127). Ils ont leur propre "logique » et Martine Segalen met justement en garde contre une vision trop économiste des choses : «il faut cesser de ne voir dans les pratiques matrimoniales que les correctifs hautement fonctionnels d'un système d'héritage " (ibid. : 160). Les échanges, cependant, ne sont pas orientés, il n'y a ni cycles ni bouclages; la consanguinité n'est qu'un sous-produit des ré-enchaînements et elle n'est nullement systématique. Cette vision des choses est parfaitement acceptable pour la période historique (fin XVIII ${ }^{\mathrm{e}} \mathrm{XIX}^{\mathrm{e}}$ siècle) prise en considération. J'essaierai de montrer que la multiplication, au XIX siècle, des mariages dans l'affinité très proche (lévirat et sororat), des mariages consanguins eux aussi de plus en plus proches, des mariages dans le même nom, des mariages dans les «lignages " des mères a entraîné, paradoxalement, la destruction de tous les mécanismes d'organisation préférentielle des échanges qui prévalaient encore au XVI ${ }^{\mathrm{e}}$ et au XVII ${ }^{\mathrm{e}}$ siècle, ce qui a porté à la disparition de cycles et de bouclages consanguins réguliers pour ne laisser subsister, pendant un court laps de temps, que des ré-enchaînements construits de manière aléatoire dans le champ des seules parentèles. 
L'interprétation de Martine Segalen s'oppose, en partie, à celle de Françoise Héritier sur les sociétés semi-complexes d'alliance, dans lesquelles «des bouclages consanguins peuvent avoir lieu, avec des cheminements préférentiels dès que les interdits cessent de s'exercer " (1981: 114). Dans les sociétés complexes, les possibilités de redoublements d'alliances different mais le principe de bouclages réguliers subsiste.

C'est sur la présence ou l'absence, dans notre monde européen occidental, d'un système organisé ou non de l'alliance que je voudrais intervenir ici. Il ne s'agit pas simplement de mettre en évidence ou de nier, l'existence d'un "échange des femmes" et, éventuellement, des règles qu'il suit ; s'il y a échange des femmes, il y a présence de groupes échangistes et il faut alors comprendre comment ceux-ci se construisent et s'articulent, ce qui amène à reconsidérer la question des groupes de parenté, voire celle de la filiation. Dans une telle perspective, les relations que l'économie et la politique entretiennent avec l'ensemble des échanges matrimoniaux, relations qui ne seront, peut-être, ni de même nature ni de même ordre que celles supposées précédemment, devront-elles être repensées? Le problème des rapports entre parenté-alliance et processus de production, reformulé par Jack Goody dans son étude sur la famille et le mariage en Eurasie (1990), devra-t-il être, de la même manière, dans le cas de l'Europe occidentale au Moyen Âge et pendant la période moderne (XVI ${ }^{\mathrm{e}}-\mathrm{XVIII}{ }^{\mathrm{e}}$ siècle), précisé ou reconsidéré ?

Sur le plan méthodologique, il faut prendre garde, je crois, à ne pas limiter l'analyse à l'étude des textes juridiques ou religieux (les interdits canoniques de parenté et d'alliance, le verset «ils seront deux en une seule chair"), qui peuvent s'avérer fort éloignés des comportements réels. Surtout, rien ne nous assure que les règles écrites cernent la totalité des jeux de l'échange; d'autres règles plus profondes, non exprimées clairement, peuvent parfaitement être à l'œuvre. L'historien - mais cela vaut aussi pour l'anthropologue, en particulier lorsqu'il tente de donner une dimension historique à son enquête - ne peut s'arrêter à la seule "rationalité " (entendons par-là une fonctionnalité explicitée de manière " cohérente ") que nos sociétés donnent à voir. Il doit, à travers l'étude des relations d'alliances effectivement pratiquées, tenter de retrouver le dit et le non-dit avec les fonctions respectives qui en découlent et leurs éventuelles articulations.

Il est vrai que pour la période du XIII-XIVe jusqu'au XVII siècle inclus que je prendrai ici en considération ${ }^{1}$, les généalogies de familles européennes

1. Avant et après cette période, les « règles " fondamentales qui président aux échanges matrimoniaux apparaissent différentes. Le "système " n'est pas immobile, il change et l'un des enjeux futurs de cette contribution est aussi de poser les bases d'une recherche et d'une compréhension des transformations, essentielles dans l'histoire du monde occidental, qui ont affecté, dans le domaine de la parenté et de l'alliance, les $\mathrm{XI}^{\mathrm{e}}$ et XIII ${ }^{\mathrm{e}}$ siècles, puis les XVIII ${ }^{\mathrm{e}}$ et $\mathrm{XIX}^{\mathrm{e}}$ siècles. 
nobles ou roturières ne se prêtent souvent qu'à une lecture confuse des principes de parenté et de filiation sur lesquels elles se fondent et des échanges matrimoniaux qu'elles transcrivent. Du nord au sud de l'Europe, d'une classe sociale à une autre, mais parfois aussi au niveau d'une même région ou de groupes sociaux juridiquement définis, les différences semblent considérables. En Haute-Lotharingie, certaines familles nobles (les Berg, les Merode, les Ligne, etc.) ${ }^{2}$ se présentent sous forme de groupes imposants, aux ramifications multiples, alors que d'autres se limitent à deux ou trois lignées; les échanges matrimoniaux apparaissent, dans certains cas, récurrents, les mêmes noms de famille revenant invariablement pendant des périodes parfois fort longues, dans d'autres, constamment renouvelés, à tel point qu'un "allié" ne se représente jamais une deuxième fois. Les accidents démographiques peuvent être à l'origine de la situation de telle ou telle famille mais on ne saurait se contenter de ce type d'explication. Les généalogies sont, la plupart du temps, l'œuvre d'historiens récents (XVI- $\mathrm{XX}^{\mathrm{e}}$ siècle) ayant travaillé sur une documentation éparse ou sur des esquisses de filiation anciennes, objet de manipulations importantes et difficiles à déceler. Les contrastes que nous relevons peuvent découler du hasard de la conservation des sources ou des choix arbitraires des auteurs qui se sont intéressés aux seules lignées principales ou ont annoté de manière incomplète les épouses et leur filiation. Mais ils peuvent également trouver leur origine dans des substrats culturels qui doivent être préliminairement précisés pour comprendre ce qu’une généalogie nous dit réellement.

Toujours en Haute-Lotharingie, la fragmentation des familles et le renouvellement constant des alliances n'expriment en fait que la persistance, jusqu'aux derniers siècles du Moyen Âge, de comportements hérités d'un système à Maisons : une personne et sa descendance adoptent le nom de la seigneurie dont ils deviennent les maîtres. L'accélération de la circulation des biens débouche alors sur un tourbillon de noms difficile à contrôler. Lorsque l'on peut rétablir les filiations consanguines de manière précise, on s'aperçoit que des personnes, des familles, des alliés portant des noms différents sont, en réalité, parents et remontent, par voie masculine, à un tronc commun plus ou moins ancien. La «dispersion » des alliances n'est alors qu'un masque qui cache des reprises fréquentes et une endogamie bien contrôlée. Lorsque, dans la seconde moitié du XIV siècle,

2. Généalogies des familles nobles dans l'Europäische Stammtafeln, neue Folge, Band VI-VII : Familien des alten Lotharingien, Marburg, J. A. Stargardt, 1978-1979, 2 vol. Une partie de ces familles ont été reprises dans le volume XVIII : Zwischen Mass und Rhein, Frankfurt-am-Main, Vittorio Klostermann, 1998. 
Gerhard I Berthout épouse Margareta Berlaer, il s'unit en réalité à une représentante d'une branche patrilatérale de sa propre famille ${ }^{3}$. De telles situations sont fréquentes jusqu'aux $\mathrm{XIV}^{\mathrm{e}}$ et $\mathrm{XV}^{\mathrm{e}}$ siècles et se présentent encore parfois en plein $\mathrm{XVI}^{\mathrm{e}}$ : l'union, dans les années 1550, de Pierre de Trazegnies-Longueville et de Marie de Hamal est celle de deux cousins parallèles patrilatéraux au $3^{\mathrm{e}} / 4^{\mathrm{e}}$ degré; mariés vers la même époque, Johann von Berchem et Henriette von Raenst sont cousins parallèles patrilatéraux au $5^{\mathrm{e}}$ degré $^{4} \ldots$ Ces réalités résiduelles sont le reflet de l'ancien système de parenté et d'alliance qui a dominé, dans de nombreuses régions, jusqu'au XIII et début du XIV ${ }^{\mathrm{e}}$ siècle et dont une des caractéristiques essentielles résidait dans la dissociation entre relation de parenté et identification onomastique des personnes (à travers l'énumération de la chaîne des ancêtres ou par accolement du nom de la seigneurie). C'est au début du XIII e siècle que les Berthout se divisent, avec les frères Walter VI, Heinrich I et Egidius, en trois branches, Melcheln, Berthout et Berlaer. Il en résulte que les enfants de Walter VI ont pour cousins parallèles patrilatéraux des personnes qui se dénomment Berthout et d'autres Berlaer. Inversement, les Berthout ont pour cousins des Melcheln et des Berlaer. Agnès, la sœur de Walter, Heinrich et Elgidius, aura des enfants qui seront cousins croisés matrilatéraux avec des Melcheln, des Berthout, des Berlaer. L'onomastique ne permet pas de distinguer les différents types de cousins qui restent donc indifférenciés avec toutes les difficultés que cela peut comporter au niveau de la définition et de la constitution d'éventuels groupes échangeurs.

Le problème se pose en réalité à tous les niveaux. Dans le volume VI de l'Europäische Stammtafeln (1978), rien ne permet d'établir un lien entre les Clèves et les Geldern qui, par ailleurs, nouent entre eux, dès les XII ${ }^{\mathrm{e}}$ et $\mathrm{XIII}^{\mathrm{e}}$ siècles, de nombreuses alliances matrimoniales. Le volume XVIII (1998) intègre les résultats de nouvelles recherches et fait remonter les deux familles au $\mathrm{XI}^{\mathrm{e}}$ siècle, jusqu'à un même ancêtre commun. Une segmentation à travers les deux frères Gerhard Flamens et Rutger I entraîne l'attribution de noms nouveaux à chacune des branches, et les mariages successifs entre les deux familles se définissent alors comme des alliances entre cousins parallèles patrilatéraux. Inversement, à Manduria, aux XVI ${ }^{\mathrm{e}}$ et XVII ${ }^{\mathrm{e}}$ siècles ${ }^{5}$, les homonymies sont extrêmement fréquentes et la réapparition d'un même nom parmi les alliés ne signifie nullement que

3. Cf. Europäische Stammtafeln..., op. cit. : VIII, 26-27.

4. Cf. Ibid. : 3-4 et 30-31.

5. Notre source principale pour Manduria est le Libro Magno delle Famiglie di Manduria, 2 vol. (Bibliothèque communale de Manduria, section Manuscrits). Voir infra: p. 81. 
nous sommes en présence de personnes appartenant au même groupe de parenté. Le patronyme le plus fréquent, celui des Micella, se réfere, en réalité, à six familles différentes, dont deux très nombreuses originaires respectivement de Manduria (Micella) et d'Hostuni (Micella alias Miciela). Lorsque la documentation ne permet pas de rétablir la position exacte de chaque personne, les risques de confusions et d'erreurs deviennent vite très élevés.

Si les scissions internes à une famille et la diversité des noms qui en découle peuvent cacher des parentés plus ou moins proches, l'uniformisation forcée des noms peut déboucher sur un résultat inverse. Le processus de consolidation des États modernes s'est accompagné, de la part de l'Église comme des monarchies, d'une volonté précise d'imposer des mécanismes de dénomination en suivant les descendances patrilinéaires. À Manduria, les rédacteurs du Libro Magno se sont efforcés de retrouver derrière les surnoms, encore fréquents au XVI ${ }^{\mathrm{e}}$ siècle, les noms de famille "véritables » pour consolider la construction strictement patrilinéaire et unifiée de leurs généalogies. Ils ont dressé, en fin de volume, une longue liste de ces changements de noms qui souligne l'importance du phénomène ${ }^{6}$. En France, en 1413, Philippe de Poitiers se considère un Dormans par les femmes et en conséquence revendique le nom et les biens de cette famille sans descendants mâles, mais il se heurte au procureur du roi pour qui « le nom de Dormans est mort si n'y fault point avoir regard ». Lors des révisions de noblesse effectuées sous le règne de Louis XIV, certaines familles encore organisées en Maisons eurent la désagréable surprise de se voir imposer des généalogies par voie uniquement masculine qui les faisaient parfois remonter à de bien peu nobles ancêtres.

Il convient de noter que si la mobilité des noms est encore importante aux XV et $X^{\mathrm{e} V I}{ }^{\mathrm{e}}$ siècles, elle semble se limiter, auX XVII ${ }^{\mathrm{e}}$ et XVIII ${ }^{\mathrm{e}}$ siècles, à des situations spécifiques dans lesquelles le nom de famille invariable attaché à la filiation "légale" et légitime reste connu. Ainsi, les différenciations entre les nouvelles branches des Cibot de Limoges avec attribution de nouveaux noms ne parviennent plus à effacer le nom de famille général

6. Cf. le Libro Magno..., op. cit. Voici quelques exemples des indications reportées dans cette liste: «La Famiglia Camerata propriamente è Della Mina ; oggi ritiene il nome Di Solito da Maria Giorgina di Solito con la quale si accasò Vicenzo Della Mina che per sopranome fù detto Camerata " ("La famille Camerata en réalité est Della Mina; aujourd'hui elle tient le nom de Di Solito pris de Maria Giorgina Di Solito qu'épousa Vincent Della Mina qui fut surnommé Camerata "); "La Famiglia di Montescaglioso, e quella che va scritta sotto il nome Di Monopoli al fol. 1705, oggi si tiene Greca" ("La famille de Montescaglioso est celle qui est décrite sous le nom de Di Monopoli au folio 1705, aujourd'hui Greca "); "La Famiglia Ruccio del fol. 1805, modernamente è detta Andrisana, differisce poi dall'Andrisana dal fogl. 35" ("La famille Ruccio au folio 1805, est dite au moderne Andrisana, et differe de l'Andrisana partant du folio 35 "). 
de Cibot (Ruchaud et al. 1993). Là où les filiations ne peuvent être reconstituées de manière précise, j’ai donc considéré les données concernant la correspondance des noms entre époux comme un indicateur, certes non exact mais suffisamment révélateur, de l'importance des unions entre cousins, sans considération de degré, parallèles patrilatéraux.

Pour cerner tous ces problèmes et en éviter les pièges, j'ai travaillé, dans toute la mesure du possible, sur des sources inédites ou publiées permettant de rétablir la filiation exacte, aussi bien par les hommes que par les femmes, de tous les individus et de remonter à un ancêtre commun. Le Libro Magno delle Famiglie di Manduria est sans doute le document le plus complet et le plus précis que l'on puisse trouver dans ce domaine - la position des femmes dans les chaînes généalogiques y est toujours connue exactement -, et c'est pourquoi je partirai d'abord de lui.

Les autres ensembles documentaires que j'ai retenus sont tous des " reconstructions " effectuées par des historiens ou des érudits locaux à partir de données tirées de registres paroissiaux, d'actes notariés (contrats de mariage, testaments, etc.) et d'autres sources variées (livres de raison, mémoires, etc.) plus ou moins longues et précises. Les généalogies présentent alors un degré de précision et d'exhaustivité moindre que celles de Manduria et les comparaisons doivent toujours être conduites avec précaution. Un des ensembles les plus complets et intéressants est celui des familles du Boulonnais - essentiellement des laboureurs -, élaboré à partir des données des registres paroissiaux et des actes notariés et publié par Pierre Daudruy, complété ensuite par Henri Lorge et Jean-Marie Boulanger (1983 et 1993) et, plus récemment, par des chercheurs locaux (données accessibles sur internet). Il se prête à des comparaisons fines avec les résultats que l'on peut tirer du corpus de Manduria. Les autres ensembles retenus concernent un groupe relativement compact de familles de Guillestre et de Champoléon dans les Hautes-Alpes (www.geneanet.org), les familles de l'élite locale de Verviers (actuelle Belgique) (Hanquet 1957 ; Le Pas de Sécheval 1990 ; Plouy 1965), la totalité des familles de Fégréac, petit village de l'Ouest français, au sud de Redon (Tables de Fégréac 2006 ; www.geneanet.org) et, enfin, les Cibot de Limoges (Ruchaud 1993), immense "lignage " dont la plupart des représentants, au XVI ${ }^{\mathrm{e}}$-XVIII ${ }^{\mathrm{e}}$ siècle, sont inscrits à la corporation des bouchers de la ville. Je n'ai pas pris en considération, pour cette première approche, la situation des familles nobles, si ce n'est pour préciser, en contrepoint, des évolutions d'ordre général; non pas qu'elles suivent un système différent de celui activé par les roturiers mais elles connaissent des évolutions souvent fortement décalées par rapport à ces derniers (par exemple en ce 
qui concerne les mariages consanguins très proches), et les possibilités de manipulations des règles d'échange et de la documentation généalogique elle-même y sont beaucoup plus grandes.

Je ne m'intéresserai à la noblesse que dans une seconde phase de cette recherche, ce qui permettra alors de préciser le jeu complexe de la dialectique socioculturelle entre les différents groupes sociaux et d'élargir le cadre géographique et chronologique de cette approche.

\section{Côté père, côté mère}

À Manduria, le premier ensemble familial décrit dans le Libro Magno est celui des d'Agostina alias Maiorana, représentatif de la plupart des autres familles du village. Le "lignage " ${ }^{7}$ se présente, dès le début du XVI ${ }^{e}$ siècle, divisé en deux branches issues de deux cousins, Cicco et Paolo, plus une troisième dénommée simplement Maiorana, décrite dans une autre partie du document où il est précisé, en marge, qu'elle est probablement de la même famille que les D’Agostina ${ }^{8}$. La lignée de Cicco s'éteint dans la première moitié du XVII ${ }^{\mathrm{e}}$ siècle tandis que celle de Paolo donne des descendants jusqu'au XVIII ${ }^{\mathrm{e}}$ siècle. Les Maiorana disparaissent assez rapidement, dans la seconde moitié du XVI siècle, mais le nom est alors repris par une lignée issue de Paolo "qui retint le nom Maiorano »?. Tout cela représente 132 mariages (plus 13 pour les premiers Maiorana) étalés sur deux siècles et demi ce qui, comme le montre le tableau 1 en annexe, en fait un groupe familial de dimensions moyennes. Au niveau des alliances, on constate un retour fréquent des mêmes noms. Vers le milieu du $\mathrm{XVI}^{\mathrm{e}}$ siècle, Flori D’Agostina, fille de Paolo, s'unit à Battista Mera; par la suite, un neveu de cette même Flori, Gregorio D’Agostina, épouse une Mera, imité, une génération plus tard, par un petit-neveu d'une autre lignée. Au milieu du XVIII ${ }^{e}$ siècle encore, Giuseppe D’Agostina, descendant direct de Paolo épouse Agata Lucia Mera. Dans la branche de Cicco, deux petitsfils de ce dernier épousent des Mera, puis encore deux arrière-petits-fils d'une lignée différente de la précédente. Les choses se disposent de la même manière avec la plupart des autres familles alliées : les Eraria, les Palmera, les Dimitri, les Pantechi, les Pasanisa réapparaissent constamment d'une lignée à l'autre des D'Agostina. Cette situation se retrouve, de manière plus ou

7. Ici, comme partout ailleurs dans le texte, j'emploie ce terme pour désigner un groupe de descendance masculin issu d'un même ancêtre commun et portant le même patronyme, ce qui n'implique pas nécessairement une filiation de type unilinéaire.

8. "Si crede l'istessa con la famiglia d'Agostino" ("On croit qu'elle est la même que la famille D’Agostino").

9. "Che ritenne il cognome Maiorano». 
moins accentuée, dans tous les autres « lignages » du village et il faut considérer des ensembles démographiquement très réduits, en dessous d'une dizaine de mariages, pour ne pas relever de tels retours d'alliés.

Des constatations du même ordre peuvent être faites, en prenant toutes les précautions méthodologiques signalées précédemment et sans, pour l'instant, nous livrer à l'analyse d'exemples précis, pour les familles du Boulonnais, pour celles de Verviers, de Guillestre et de Fégréac. On y retrouve des schémas d'échanges très semblables. Il est cependant trop tôt pour affirmer que de tels mécanismes se retrouvent partout dans l'Europe chrétienne héritière du catholicisme romain ${ }^{10}$. Non seulement les «marges orientales " - Pologne, Prusse, Hongrie... - posent problème, mais plus globalement toute l'Europe du Nord, à commencer par l'Angleterre, présente des particularités marquées, ce qui ne signifie pas forcément que le système y est différent. Je reviendrai sur cette question par la suite.

On peut expliquer les réplications continues d'alliances avec les mêmes familles de manière relativement simple: dans une société où l'endogamie villageoise ou régionale reste très forte, on s'adresse inévitablement à un nombre limité de groupes familiaux alliés qui réapparaissent donc régulièrement au cours des générations. J'essaierai de montrer que cette interprétation, dont beaucoup d'historiens et parfois aussi d'anthropologues se sont contentés, n'est pas satisfaisante et que les termes doivent en être inversés : ce n'est pas l'endogamie qui entraîne des « retours" d'alliés, ce sont les règles générales qui président à ces retours qui délimitent un espace endogame plus ou moins réduit. Contrairement à Jack Goody, je crois qu'il existe, en accord avec Anita Guerreau-Jalibert (1994), dans le domaine de l'alliance, pour une longue période qui va du XIII ${ }^{\mathrm{e}}$ au XVII ${ }^{\mathrm{e}}$ siècle, des "préférences organisatrices " précises et que leur détermination est fondamentale pour comprendre le fonctionnement, non seulement de nos sociétés occidentales anciennes et les transformations qui ont pu les affecter en amont ( $\mathrm{X}^{\mathrm{e}}$-XII ${ }^{\mathrm{e}}$ siècle) et en aval (XVIII ${ }^{\mathrm{e}}$-XIX ${ }^{\mathrm{e}}$ siècle), mais plus généralement des sociétés dites cognatiques.

\section{Les mariages dans le même nom : les données générales}

Je voudrais insister sur un aspect qui n’a guère été mis en évidence par les historiens et les anthropologues et me paraît capital pour comprendre la «logique " profonde qui porte à d'éventuelles réplications d'alliances. Avant de tenter de déceler des règles qui orienteraient des reprises d'unions

10. Le monde orthodoxe héritier de Byzance suit des normes juridiques et des mécanismes de circulation matrimoniale partiellement différents de ceux du monde chrétien héritier de Rome (cf. Laiou 1992 ; Delille 2006 ; Pitsakis 2006). 
et donc de poser, dès le départ, le problème en termes positifs, il faut essayer de cerner et de comprendre ce qui, dans une famille, le long des générations, ne peut pas être répliqué. Chez les D’Agostina, un des deux ancêtres initiaux, Paolo, a épousé une Maiorana, c'est-à-dire une personne provenant d'un groupe apparenté issu probablement d'une segmentation. Nous pouvons considérer qu'il s'agit là d'un mariage "interne", de type parallèle patrilatéral. Par la suite, parmi les 144 autres mariages transcrits dans le Libro Magno, aucun ne met plus en présence un D’Agostina avec une D'Agostina (ou une Maiorana) et nous ne constatons plus l'apparition de divisions internes accompagnées de changements de noms. Pourtant, dès la fin du XVI ${ }^{\mathrm{e}}$ siècle, les descendants de Cicco et de Paolo sont éloignés de plus de quatre générations et rien ne les empêchait de multiplier, sans enfreindre aucun interdit canonique, les alliances entre eux et de se comporter comme un groupe de descendance patrilinéaire endogame. Ils ne l'ont pas fait et ont même soigneusement évité de le faire. Cette constatation vaut, comme le montre notre tableau 1 en annexe, pour tous les autres grands lignages de Manduria. Les Mera sur un total général de 324 unions, les Modea sur 264, ne se marient jamais dans leur propre nom. Les Dimitri nouent, au cours des XVI ${ }^{\mathrm{e}}$ XVII et début du XVIII siècles, 390 alliances mais ne s'unissent que 2 fois à l'intérieur de leur propre groupe patrilinéaire. Globalement, sur 4782 mariages (soit environ la moitié de ceux transcrits dans le Libro Magno), 22 seulement sont de type parallèle patrilatéral, soit une proportion de $0,46 \%$. Ces alliances n'ont donc pas de véritable incidence sur le fonctionnement du système général des échanges. À Manduria, ces rares bouclages dans les lignes masculines respectent les interdits canoniques et se situent, dans leur très grande majorité, entre le $5^{\mathrm{e}}$ et le $7^{\mathrm{e}}$ degré.

Quelle situation trouvons-nous dans le Boulonnais? Les «lignages» y sont numériquement moins importants qu’à Manduria; les Routtier célèbrent 169 mariages sur un peu plus de deux siècles, les De Habart 171, mais aucun groupe n'atteint les chiffres des Dimitri, des Mera ou des Modea. Ce n'est peut-être là qu'une conséquence des données incomplètes concernant surtout le $\mathrm{XVI}^{\mathrm{e}}$ siècle. Les filiations directes sont cependant toujours bien connues et sur 2025 mariages, 13 seulement se nouent dans la même parenté patrilinéaire ce qui représente une proportion de $0,64 \%$. Le chiffre est pratiquement identique à celui de Manduria (voir le tableau 2, en annexe). À 2000 kilomètres de distance, du sud au nord de l'Europe, les comportements des paysans, des laboureurs ou des artisans respectent une même "règle" fondamentale qui peut s'énoncer de la manière suivante :

On ne se marie pas dans la parenté masculine de son père. 
Ce que nous pouvons décliner aussi de la manière suivante: on ne se marie pas dans le même nom que son père, sauf homonymie évidente et donc absence de tout lien de parenté.

En Bourgogne, dans la vallée de la Ouche, les registres de mariages des quatre petits villages de Bligny, Lusigny, Thorey et Veuvey-sur-Ouche (www.geneabank.org) nous ont transmis, de 1582 à 1792, l'indication de 2274 unions. Sur ce total, les alliances dans le même nom sont au nombre de 17 seulement, soit une proportion de $0,74 \%$. Les variations apparaissent très limitées selon les périodes. Une première augmentation significative n'intervient que dans la seconde moitié du XVIII siècle.

Un tel comportement est très largement dominant partout en Europe. Il se diffuse parallèlement à l'affirmation des surnoms puis des noms de famille et se traduit parfois par des mesures juridiques: à Gênes et à Florence il est interdit, à la fin du Moyen Âge, de contracter mariage avec un de ses consorts ou avec une personne portant le même nom (Lett 2000). À Gênes, la règle semble s'estomper à partir du milieu du XVe siècle, mais les mariages dans le même nom ne sont, en réalité, que la conséquence d'une évolution profonde du système des alberghi qui, de clans consanguins à hérédité masculine, tendent à se transformer, progressivement, en de vastes regroupements de familles homonymes mais non apparentées.

Il faut se tourner vers des régions de montagne très isolées ou vers des familles constituant des associations de nature économique et sociale particulière (les Cibot de Limoges) pour rencontrer des exemples qui dérogent partiellement à la règle d'interdit d'alliance dans le nom. Je prendrai en considération de telles situations par la suite.

Il convient d'être toujours très attentif à la manière dont les données nous sont transmises. À Fégréac, nous relevons, à travers les généalogies des groupes familiaux les plus importants, 68 mariages dans le même nom sur un total de 2208 , soit plus de $3 \%$; ce chiffre est en partie la conséquence des reconstitutions généalogiques focalisées sur les grands lignages plus que sur les petites familles isolées. Les données des registres paroissiaux corrigent cette distorsion et donnent 2,11\% de mariages internes pour la période $1570-1600,1,80 \%$ pour la première moitié du XVII $2,60 \%$ pour la seconde moitié et $1,68 \%$ pour la première moitié du XVIII siècle. Nous restons donc sur des valeurs très basses. Dans le village voisin de Guenrouët (Tables de Guenrouët, s. d.), toujours d'après les registres paroissiaux, le taux moyen d'unions dans le même nom est, pour la période $1562-1802$, de $1,5 \%$; ce n'est que dans la première moitié du XIX ${ }^{\mathrm{e}}$ siècle que l'on constate une hausse sensible. 
Notons enfin que les alliances dans le même nom concernent généralement des «lignages" de dimensions importantes : il faut qu'une descendance se diversifie en plusieurs branches pendant au moins quatre ou cinq générations pour que, au-delà du champ prohibé des quatre degrés (sauf éventuelle dispense ecclésiastique), de tels bouclages puissent être activés. À Manduria, plus de la moitié sont le fait des Perruccia, des SchiavoneCimarra et des Stratea 1 ; même chose dans le Boulonnais avec les Delattre et les De Habart, à Guillestre avec les Chapin et les Court, à Fégréac avec les Guiho et les Bocquel. En ce sens, les Cibot de Limoges ne représentent rien d'autre que l'un de ces groupes familiaux qui pratiquent de manière plus ou moins récurrente des alliances internes. Si nous pouvions considérer tous les mariages de la ville de Limoges dans leur ensemble, il est probable que nous obtiendrions des pourcentages d'alliances dans le même nom très bas, proches de ceux des autres cas étudiés.

L'inverse, cependant, n'est pas nécessairement vrai ; comme les Mera ou les Modea à Manduria, de grands lignages comme les Daudruy et les Duflos dans le Boulonnais, les Pascal à Guillestre, les Lejeune ou les Danot à Fégréac, n'activent pas ou seulement de manière exceptionnelle et tardive (1 mariage en 1765 pour les Danot) d'unions «internes».

\section{Les mariages dans le même nom : le cadre chronologique}

Un peu partout, passées les premières décennies du XVIII siècle, les proportions de mariages dans le même nom tendent à augmenter fortement. À Manduria, sur les 22 mariages recensés, 16 se situent dans la seconde moitié du XVII ${ }^{e}$ ou au début du XVIII ${ }^{\mathrm{e}}$ siècle, tandis que le $\mathrm{XVI}^{\mathrm{e}}$ et la première moitié du XVII ${ }^{\mathrm{e}}$ siècle apparaissent presque totalement vides. La majorité de ces unions internes relève donc d'une évolution qui tend à favoriser, à la fin du XVII et au XVIII ${ }^{e}$ siècle, de manière encore très limitée, ce type de relations. Ce mouvement ira ensuite en s'accentuant fortement. Les reconstitutions faites pour prolonger les généalogies du Libro Magno traduisent une véritable explosion de mariages internes à la fin du XVIII et pendant tout le XIX ${ }^{\mathrm{e}}$ siècle. Partout, les XVIII ${ }^{\mathrm{e}}$ et $\mathrm{XIX}^{\mathrm{e}}$ siècles marquent l'affirmation de comportements différents et plus favorables aux mariages dans le même nom, avec cependant des chronologies diverses et des proportions générales qui peuvent varier fortement d'une région, voire d'une communauté, à l'autre.

Dans le Boulonnais, la situation se renverse vers le milieu du XVIII ${ }^{\mathrm{e}}$ siècle. À Guillestre, une première poussée de mariages parallèles patrilatéraux se manifeste dès la fin du XVII et au début du XVIII ${ }^{e}$ siècle et c'est ce déphasage temporel important qui explique le taux global élevé (5\% pour 
l'ensemble de la période de la fin du XVI à la fin du XVIII ${ }^{\mathrm{e}}$ siècle) de mariages dans le même nom. Comme à Fégréac, la méthode de reconstitution généalogique aboutit à gonfler les chiffres, mais le contraste s'explique surtout par de fortes variations chronologiques : 6,70 \% dès la première moitié du XVIII ${ }^{\mathrm{e}}$ siècle, pourcentage qui se maintient ensuite pendant tout le XVIII ${ }^{\mathrm{e}}$ siècle, contre des valeurs qui oscillent entre 1,2 et $3,4 \%$ (avec une moyenne générale de $2 \%$ ) pour le XVI et le XVII ${ }^{e}$ siècle. De manière générale, les régions de montagne présentent, à toutes les périodes, des taux plus élevés et des croissances très fortes au cours des XVIII et XIX ${ }^{e}$ siècles. À Besse-en-Oisans, dans le Dauphiné, la proportion de mariages dans le même nom qui se situait autour de $4,50 \%$ au $\mathrm{XVII}^{\mathrm{e}}$ siècle, bondit à $7,16 \%$ dans la seconde moitié du XVIII ${ }^{e}$, puis à 7,76 et $9,57 \%$ au XIX siècle. À Menthoneix-en-Bornes, en Haute-Savoie, on passe de $3 \%$ à la fin du XVI et première moitié du XVII ${ }^{\mathrm{e}}$, à 6,28\% dans la première moitié du XVIII ${ }^{e}$, puis à $11,17 \%$ dans la première moitié du XIX siècle. Mais le "même nom " ne représente peut-être, dans la plupart de ces communautés, qu'une désignation artificielle imposée par le pouvoir central et qui recouvre des mécanismes d'identification plus articulés et changeants sur lesquels je reviendrai par la suite. Dans les régions de plaine, les proportions et les évolutions sont souvent très proches de celles rencontrées à Manduria ou dans le Boulonnais. À Montreuil-sousBois (www.geneabank.org), près de Paris, le taux s'établit à 0,35\% dans la seconde moitié du XVI siècle et $0,36 \%$ dans la première moitié du XVII . Il croît légèrement $(0,58 \%)$ dans la seconde moitié du XVII siècle, puis décidément dans la première moitié du XVIII $(1,37 \%)$. Mais alors, le mouvement s'arrête: pris dans la croissance urbaine de la capitale, Montreuil connaît un renouvellement considérable de sa population et les nouveaux venus, isolés ou très mobiles, ne pratiquent pas, comme les vieilles familles du lieu, de mariages dans le même nom.

À Frégéac, d'après les registres paroissiaux de mariage, l'augmentation des unions dans le même nom, d'abord lente à partir du milieu du XVIII siècle, s'accélère vers 1770 pour exploser ensuite pendant la décennie révolutionnaire 1790-1800. Le taux voisin ou inférieur à $2 \%$ constaté de 1570 à 1750 bondit alors à plus de $4 \%$ et oscille entre 4,5 et 5,5\% pendant tout le XIX ${ }^{\mathrm{e}}$ siècle. Les registres paroissiaux permettent de comprendre les modalités de cette évolution : jusque vers le milieu du XVII ${ }^{\mathrm{e}}$ siècle, les alliances dans le même nom sont presque exclusivement le fait de deux grands lignages, les Guiho et les Bocquel, qui maintiennent ensuite ce comportement jusqu'à la fin du XIX siècle. En 1642 puis 1649, un autre groupe familial important, les Poulain, s'engage lui aussi dans 
la voie des unions dans le même nom pour ne plus l'abandonner jusqu'à la fin du XIX ${ }^{e}$ siècle. Les Perouze se joignent à eux en 1681-1682, suivis par les Serot en 1690, les Anneix en 1729, les Besnier en 1764... Même scénario à Guenrouët : aux Guitton, Rouxeau et Thébaud qui dominent la scène à la fin du XVI et pendant la première moitié du XVII ${ }^{\mathrm{e}}$, s'ajoutent les Gaultier et les Levesque puis, au XVIII siècle, les Bouvier, les Daniel, les Legrand... Dans le Boulonnais, ce sont les Fournier, les Dupont, les Cugny qui rejoignent les Delattre. Dans la vallée de la Ouche, les unions dans le même nom sont l'apanage des Boudier à Thorey, des Drouhin à Lusigny et surtout des Favelier à Bligny et Lusigny. Les Dauphin, les Rousseau, les Collenot, les Rivot viennent s'ajouter à ces premières familles dans la seconde moitié du XVIII ${ }^{\mathrm{e}}$ siècle. À Guillestre, le grand lignage des Michel multiplie, au XVI siècle, les mariages internes. Il disparait ensuite mais est remplacé dès la première moitié $\mathrm{du} X V \mathrm{XI}^{\mathrm{e}}$ siècle par les Brun, suivis dans les années 1660-1670 par les Chapin et les Court puis, au XVIII e, par les Albert, Argence, Barthélémy. À Montreuil, on enregistre une première union entre deux Vitry, en 1551 ; elle sera suivie, jusqu'en 1837, par 22 autres, ce qui représente plus de $40 \%$ des mariages dans le même nom. Les Beausse et les Savart les rejoignent respectivement en 1702 et 1716, mais le mouvement s'arrête ensuite et les Chevalier ou les Mainguet ne font que de timides apparitions à la fin du XVIII ${ }^{\mathrm{e}}$ et au XIX siècle.

L'évolution se réalise donc par ajouts successifs de nouvelles familles aux anciennes et, à la fin du XVIII et au XIX siècle celles qui, enracinées dans le terroir, ne célèbrent pas, à un moment ou à un autre, une union dans le même nom sont devenues l'exception alors qu'elles représentaient la règle aux $\mathrm{XVI}^{\mathrm{e}}$ et $\mathrm{XVII}^{\mathrm{e}}$ siècles. Nous sommes là en présence de la diffusion progressive d'un modèle et d'une "idéologie " qui réfute une des bases fondamentales du système, celle de la similitude entre nom et parenté.

La nature et l'importance des changements qui interviennent au cours des XVIII ${ }^{e}$ et XIX ${ }^{e}$ siècles ne tiennent pas cependant à la seule multiplication des mariages dans le même nom. Dans certains cas, la croissance est relativement limitée et elle pourrait être interprétée comme une simple fluctuation conjoncturelle sans conséquences sur le système général des échanges. La hausse des courbes s'accompagne, en réalité, de changements qualitatifs profonds, en particulier d'un resserrement de plus en plus marqué des bouclages consanguins. Alors qu'au XVI ${ }^{\mathrm{e}}-\mathrm{XVII}{ }^{\mathrm{e}}$ siècle, les unions entre parents parallèles patrilatéraux se situent, comme je l'ai souligné à diverses reprises, pour l'essentiel, entre les $4^{\mathrm{e}} / 7^{\mathrm{e}}$ degrés de consanguinités, aux XVIII ${ }^{e}$ et $\mathrm{XIX}^{\mathrm{e}}$ siècles, elles se nouent, de manière toujours plus 
fréquente, vers les $2^{\mathrm{e}} / 3^{\mathrm{e}}$ degrés. Guy Tassin (2007) l'a bien montré dans le cas du petit village d'Haveluy, dans le nord de la France : dans le cadre d'une explosion générale de mariages entre cousins germains de tous types, ceux entre parallèles patrilatéraux progressent plus rapidement que les autres. L'évolution est la même à Fégréac, à Guillestre ou à Manduria ; c'est tout le système qui bascule.

Si l'empêchement de mariage dans le même nom connaît de profondes transformations au cours des XVIII et XIX ${ }^{e}$ siècles, nous pouvons penser qu'il a pu en être de même à d'autres époques précédentes. Les données antérieures au XVI ${ }^{\mathrm{e}}$ siècle concernant les classes roturières sont trop fragmentaires et trop incertaines quant à la filiation et à la parenté des personnes pour pouvoir apporter une réponse à cette question. En contrepoint, les indications concernant la noblesse permettent de mieux cerner le problème. J'ai relevé, pour cela, dans les généalogies de familles nobles publiées dans l'Europäische Stammtafeln, pour un certain nombre de régions européennes ${ }^{11}$, les unions entre cousins parallèles patrilatéraux (portant ou non le même nom de famille), du XIII ${ }^{e}-\mathrm{XIV}^{\mathrm{e}}$ siècle jusqu'au XVIII ${ }^{\mathrm{e}}$ siècle.

\begin{tabular}{|c|c|c|}
\hline & $\begin{array}{l}\text { BOURGOGNE AU MOYEN ÂGE } \\
\text { FAMILLES FÉODALES DE FRANCE }\end{array}$ & $\begin{array}{c}\text { HESSE-SAXE } \\
\text { (familles Hohenlohe, } \\
\text { Solms, Ysenburg) }\end{array}$ \\
\hline $\begin{array}{l}X \|^{e}-X \mid I^{e} \text { siècle } \\
\text { (I | } 50 \text { - | } 300 \text { env.) }\end{array}$ & 85 & Données insuffisantes \\
\hline XIVe siècle & 31 & 9 \\
\hline XVe siècle & 17 & 0 \\
\hline $\mathrm{XVI} \mathrm{I}^{\mathrm{e}}$ siècle & 10 & 1 \\
\hline $\begin{array}{l}X V\left\|^{e}-X V\right\| I^{e} \text { siècle } \\
(\mid 600-1750 \text { env. })\end{array}$ & 42 & 13 \\
\hline
\end{tabular}

Évolution du nombre de mariages parallèles patrilatéraux dans les familles nobles de Bourgogne, les familles féodales de France et de Hesse-Saxe (XII -XVIII siècle)

11. Avec tous les problèmes méthodologiques que nous avons déjà soulignés. Il faut toujours, dans la mesure du possible, reconstituer les généalogies ascendantes des époux. Les unions entre les Clèves et les Geldern sont de types parallèles patrilatérales et il en va de même dans la Maison de Toulouse pour les mariages entre les Comborn, les Ventadour et les Turenne. Très souvent, ces segmentations et changements de noms nous restent inconnus et il ne fait pas de doute que le nombre de mariages parallèles patrilatéraux s'en trouve, pour le $\mathrm{XII}^{\mathrm{e}}-\mathrm{XIV}^{\mathrm{e}}$ siècle, fortement sous- évalué. 
Ces chiffres, quelles que soient les corrections qui, pour les périodes les plus anciennes, pourront leur être apportées, traduisent bien une très forte contraction, voire, dans certains cas, une disparition des mariages « internes" pendant une longue période qui s'étend approximativement, dans le cas de la noblesse, du milieu du XIV ${ }^{\mathrm{e}}$ au milieu du XVII ${ }^{\mathrm{e}}$ siècle.

La première règle fondamentale énoncée à partir des exemples de Manduria et du Boulonnais, "on ne se marie pas dans la parenté masculine de son père", semble donc, avec d'amples oscillations au niveau régional et selon les groupes sociaux, avoir valeur générale pour une période historique qui s'étend à peu près du milieu du XIV e au milieu du XVIII ${ }^{\mathrm{e}}$ siècle. À partir de la fin du XVI e siècle dans la noblesse et du milieu $\mathrm{du} \mathrm{XVII}^{\mathrm{e}}$ dans les classes "populaires ", ce comportement est progressivement ignoré par un nombre toujours plus grand de familles et finit par être largement rejeté au XIX ${ }^{\mathrm{e}}$ siècle, période pendant laquelle les mariages dans le même nom sont, partout, nombreux.

Le système de transmission patrilinéaire du nom de famille qui s'est imposé à partir des XII ${ }^{e}$ et XIII ${ }^{\mathrm{e}}$ siècles débouche sur la définition, dans le déroulement des générations, de groupes de descendance masculins parfaitement définis et exogames. Dans la plupart des exemples que j’ai pris en considération, il apparaît que cette exogamie ne pose aucune limite temporelle à son action. Il n'y a donc plus, comme nous l'avons vu encore dans le cas des D'Agostina-Maiorana et comme nous le verrons, chez les Cibot, jusque vers la fin du XVII siècle, activation de mécanismes qui divisent et distinguent, éventuellement par attribution d'un nouveau nom, une partie de la descendance de l'autre, leur permettant ensuite de nouer de nouvelles alliances entre elles. Il n'y a plus de segmentations.

Le rejet du mariage dans le même nom traduit un empêchement de fait et parfois de droit ; il n'est pas nécessairement en contradiction avec les interdits canoniques traditionnels en matière de consanguinité et d'affinité qui couvrent des aires générationnelles différentes. On voit bien, dans ce cas précis, l'erreur que l'on commet en partant du droit pour analyser la réalité sociale : cette dernière ne "colle " pas au droit, elle le dépasse, sans nécessairement le nier. À focaliser, comme on le fait généralement, la parenté et l'alliance en Europe occidentale à travers la seule lentille des quatre degrés interdits - aussi bien par voie masculine que féminine -, on ne saisit qu'une partie de la réalité. Ce rejet du mariage dans le même nom débouche sur une conséquence importante : s'il existe encore dans nos sociétés occidentales historiques des "préférences» qui organisent l'alliance, des échanges directs des femmes et des bouclages dans la parenté - cela n'étant, pour l'instant, qu'une hypothèse de travail -, alors ceux-ci se construisent à travers des chaînes de consanguins comportant nécessairement au moins un maillon féminin. 
Si on ne peut pas se marier dans le même nom, on ne peut pas avoir ceci :

Il faut donc, au minimum, avoir cela:

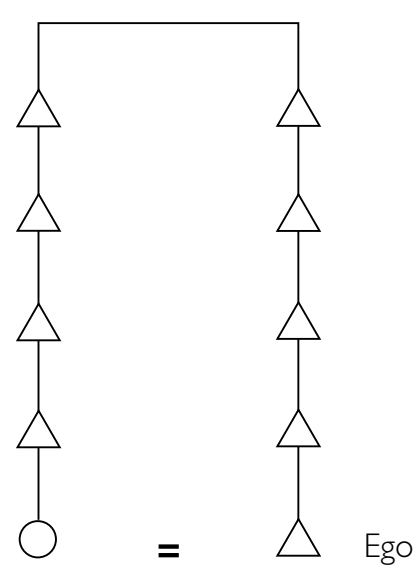

Bouclage $n^{\circ} \mathrm{I}$

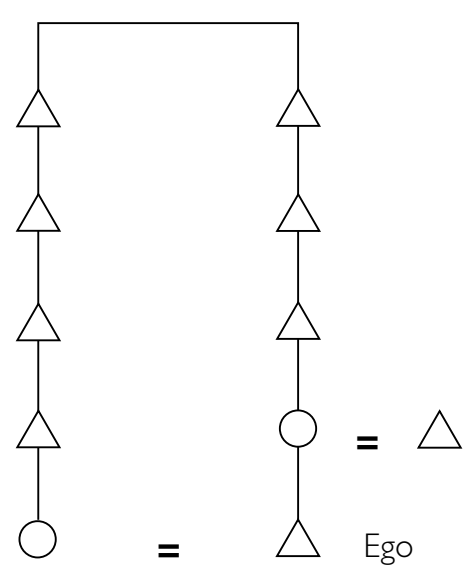

Bouclage $n^{\circ} 2$

Pour éviter le "lignage " du père, il suffit de s'adresser soit à un lignage étranger, soit à celui de sa mère. Dans ce dernier cas, la nécessité, imposée par le droit canon, de remonter jusqu'à des ancêtres au-delà du $4^{\mathrm{e}}$ degré apparait, d'une certaine manière, superflue. Un mariage avec une cousine croisée matrilatérale (schéma caractéristique d'un système lignager exogame) suffirait pour que l'empêchement de mariage dans le même nom soit respecté :

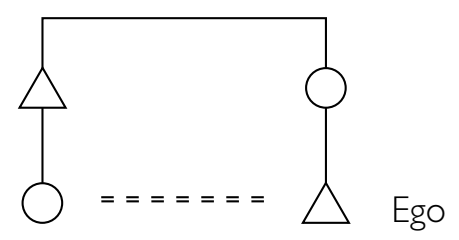

Mais peut-on se marier du côté de sa mère?

Retournons à nos généalogies. Cicco D’Agostina a épousé, vers la fin du XVe-début du XVI ${ }^{e}$ siècle, une Calò. Ce dernier nom ne se représentera plus jamais, en tant quallié, parmi les descendants directs de Cicco. À la génération suivante, deux de ses trois enfants mâles épousent l'un une Liuzza, l'autre une Di Lorenzo, noms qui disparaissent, une fois encore, de leurs descendances respectives. Le troisième garçon, Guarino, s'unit à 
Sempronia Bonifacia et noue, on ne sait à quel moment, une relation illégitime avec Rosata Dorante ce qui - le concile de Trente vient à peine de commencer - ne semble guère affecter la situation de leurs bâtards. Les Bonifacia n'apparaissent plus dans la descendance de la première union, les Dorante dans celle de la seconde. En revanche, deux filles nées de l'épouse Bonifacia s'unissent à des Dorante, parents proches (respectivement cousins au $2^{\mathrm{e}} / 3^{\mathrm{e}}$ et au $2^{\mathrm{e} / 4^{\mathrm{e}}}$ degré) de Sempronia. On peut se marier dans la parenté d'une belle-mère, pas dans celle de la mère, comme inversement on peut se marier dans la parenté d'un beau-père, non dans celle du père.

Toutes les familles du village se comportent, une fois encore, comme les D’Agostina. Au début du XVI siècle, Francesco Pasanisa épouse Donna Scialpa. Ils sont à l'origine d'une descendance nombreuse que nous pouvons suivre jusqu'au milieu du XIX siècle : à aucun moment le nom de Scialpa n'y réapparaît comme allié. Parmi les frères de Francesco, Giovanni, Carlo, Dragonetto s'unissent à une Franciosa, une De Strati et une Micella 2, noms qui disparaissent, une fois encore, de leurs descendances respectives. C'est seulement dans la lignée de Bernardino, dernier frère de Francesco, que le nom de l'«ancêtre féminin ", Di Lorenzo, se représente quatre et cinq générations plus tard.

Je pourrais, pour Manduria, multiplier les exemples à l'infini. J'ai indiqué dans le tableau 1 en annexe, à partir du même échantillon analysé pour les mariages dans le nom du père, le nombre de reprises d'alliances dans la parenté masculine de l'une des épouses de la lignée ascendante masculine de Ego ${ }^{12}$. Elles sont au nombre de 78, soit une proportion de $1,63 \%$. Le chiffre, très bas, ne permet pas de conclure à des bouclages systématiques dans la parenté masculine des mères. Il est cependant un peu plus élevé que celui concernant les unions dans le lignage du père ce qui peut signifier simplement que le nom et le sang des mères, à la différence de ceux des pères, finissent par s'oublier.

Comment se présentent les choses dans le Boulonnais? Exactement de la même manière. Vers 1525, Marc Hamerel épouse Jehenne des Trois Maisons. Leurs descendants, très nombreux, ne s'adresseront plus jamais, jusqu'à la fin du XVIII ${ }^{e}$ siècle, aux Trois Maisons pour leur demander une femme ou leur en offrir une. Les trois fils mâles de Marc et Jehenne s'unissent à une Coze, une Huault et une Routtier, et, là encore, ces noms disparaissent, en tant qu'alliés, dans leurs descendances directes respectives.

12. Pour la clarté du discours, nous qualifierons donc la mère, la grand-mère paternelle, l'arrièregrand-mère paternelle... et, plus globalement, toutes les épouses de la lignée ascendante directe masculine d'un Ego, du terme général de "les mères ". À la différence de l'enquête concernant les mariages dans le lignage du père, celle sur les bouclages dans les lignages des mères ne peut être conduite qu'à partir d'ensembles documentaires indiquant la filiation des personnes. 
Toutes les familles du Boulonnais se comportent de la même manière: 22 mariages sur 2025, soit un peu plus de $1 \%$, relèvent d'un retour d'alliances dans le lignage d'une des mères de la lignée ascendante directe.

Une fois encore, à 2000 kilomètres de distance, je relève des comportements identiques qui traduisent un même respect pour une autre "règle » profonde qui peut s'énoncer de la manière suivante:

On ne se marie pas dans les parentés masculines de ses mères.

Ce que nous pouvons également décliner de la manière suivante: on ne se marie pas dans le même nom que l'une des mères de sa propre lignée ascendante masculine (sauf homonymie).

Dans la plupart des communautés rurales pour lesquelles la filiation des personnes est connue, la règle apparaît strictement respectée, les exceptions ne dépassant généralement pas 1 ou $2 \%$. À Verviers, le taux avoisine les $2 \%$. À Guillestre, il s'élève à 2,9\%, inférieur - c'est un des rares exemples en ce sens - à celui des unions dans le lignage du père. Dans tous ces cas, la moyenne générale cache de fortes disparités suivant les périodes. Partout, les pourcentages sont, aux XVI ${ }^{\mathrm{e}}$ et $\mathrm{XVII}^{\mathrm{e}}$ siècles, extrêmement bas (moins de $1 \%$ ), tandis que l'augmentation est très sensible pendant la seconde moitié du XVIII et est suivie de maxima au cours du XIX siècle. Comme pour les mariages dans le même nom, le phénomène est l'apanage de quelques familles auxquelles viennent, progressivement, s'en ajouter d'autres : les Daudruy et les De Habart dans le Boulonnais, les Franquinet à Verviers, les Pascal, les Brun, les Barthélémy à Guillestre. Notons que certaines familles pratiquent à la fois des bouclages dans le lignage du père et dans le lignage d'une mère (les De Habart, les Barthélémy, etc.), mais que d'autres ne pratiquent qu'un seul type de reprise (les Daudruy, les Pascal... n'activent que des bouclages dans les lignages des mères).

La possibilité de suivre de manière très précise les généalogies pendant des temps très longs (plus de trois siècles dans le cas des Pasanisa) permet d'avancer avec certitude une autre constatation fondamentale : les exclusions se cumulent dans la descendance directe, au cours des générations. Toutes les parentés masculines des femmes épousées successivement dans la lignée masculine directe à laquelle appartient Ego sont exclues à tout jamais des alliances possibles; cela, du moins, tant que l'on conserve le souvenir de ces mères passées, un souvenir qui est, semble-t-il, très durable ${ }^{13}$.

13. Le Libro Magno lui-même a été conçu et rédigé par l'archiprêtre du village, Lupo Donato Bruno, essentiellement sur la base d'une connaissance orale remontant jusqu'à l'ancêtre commun des différentes branches d'un groupe familial, c'est-à-dire, dans la plupart des cas, bien au-delà d'un siècle. Lupo Donato indique qu'il a dû faire, pour les périodes très anciennes, quelques recherches d'archives pour préciser certaines filiations. 
L'« empêchement» multiplie, au cours des générations, les lignages « interdits » et s'applique donc, contrairement à celui concernant le lignage du père, de manière différenciée en fonction des ramifications successives auxquelles peut donner lieu une lignée initiale. À la fin du XVII ${ }^{e}$ siècle, Francesco Dimitri ne peut pas prendre femme, outre les Dimitri, dans les groupes familiaux Di Mauro, Pecorara, Gennara, Della Viola, Micella 1, Di Strati 1, Elefante, Della Mugna et Pacella, c'est-à-dire ceux de "ses mères " jusqu'à l'ancêtre connu le plus lointain ; à cela, il faudrait ajouter les lignées descendantes masculines des femmes que les Dimitri ont données en mariage dans d'autres lignages. Son cousin patrilatéral au $4^{\mathrm{e}}$ degré canonique, Francesco Paolo Dimitri, partage avec lui les mêmes interdits pour les Della Viola, Micella 1... jusqu'aux Pacella, mais les Di Mauro, les Pecorara, les Gennara lui sont autorisés et sont remplacés par les Tatulla, Valentina et Pantechi. Et ainsi de suite : Giuseppe Dimitri,

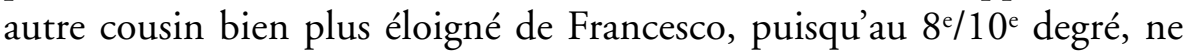
partage avec lui que l'interdit pour les Pacella. Sa lignée, en deçà de cette bifurcation ancienne pouvait prendre femmes dans toutes les autres familles, des Di Mauro aux Micella 1, et elle ne s'en est pas privée.

À la fin du XVIII e siècle, Jean Charles Pierre Marie Hamerel ne peut chercher une épouse parmi les Tillette, les Dupont, les Wiart, les Duflos, les De Lattre, les Coze et les Trois Maisons. Les cousins contemporains de Jean Charles sont tous issus de lignées qui ne partagent avec lui que l'ascendance avec les Trois Maisons; les familles Dupont, Duflos, Coze... ne leur étaient donc pas «interdites » et de nombreuses alliances ont été effectivement nouées avec elles.

Les diverses lignées descendantes d'un même ancêtre se trouvent ainsi classées, par rapport à d'autres groupes patrilinéaires considérés dans leur totalité, en épousables et non épousables, et si toute ligne de filiation directe se trouve contrainte à renouveler ses alliances à chaque génération, rien ne l'empêche - mais rien ne l'y oblige non plus - de répliquer, en fonction de la position générationnelle des différentes bifurcations, celles réalisées par des collatéraux. En ce sens, les échanges sont donc bien "orientés » et les cadres d'ordonnancement fondamentaux de ces échanges dépassent largement les limites des parentèles. L’orientation est le résultat d'empêchements négatifs qui, pour paraphraser Claude Lévi-Strauss, sont susceptibles d'une lecture positive.

La détermination des possibilités de réplications d'alliances à travers les lignées collatérales suppose la connaissance de sa généalogie ascendante ; plus ce savoir sera grand, plus les réplications pourront impliquer des lignées éloignées et plus la cohésion d'ensemble du groupe de descendance masculin sera grande. 
L'« empêchement » de mariage dans les noms des mères va, comme celui dans le nom du père, bien au-delà des quatre degrés canoniques. Il eut été très facile, dans le cas des grands lignages, de répéter les unions dans la parenté des mères ; cela n'a pas été fait et on a, encore une fois, soigneusement évité de le faire. Les reprises d'alliances dans la parenté d'une mère sont rares et, aux XVI ${ }^{\mathrm{e}}$ et XVII ${ }^{\mathrm{e}}$ siècles, elles ne sont pas l'expression de mariages consanguins proches; elles ne violent pas, dans leur très grande majorité, les interdits de l'Église. L'« empêchement » du côté des mères a, comme celui du côté du père, valeur absolue. Il pèse sur l'ensemble des descendances masculines des frères de la mère mais s'arrête, en ligne féminine, à la fille de la sœur de la mère. La parenté de la mère est perçue par Ego et ses descendants de manière globale comme un lignage. L'interdit canonique des quatre degrés complète et contredit, en partie, cette vision : la parenté masculine de la mère y est réduite à un segment de descendance sur quatre générations tandis que la parenté en ligne féminine est, au contraire, prolongée sur quatre degrés, rétablissant ainsi une stricte égalité entre passages masculins et passages féminins. La limitation du champ de l'interdit à quatre générations autorise, sur le plan légal, des reprises d'alliances aussi bien dans le lignage du père que dans celui des mères une fois cette distance générationnelle dépassée, ce que les «interdits » dans le nom du père et dans celui des mères ne permettent pas.

Ces derniers empêchements découlent de règles profondes, généralement non exprimées; ils constituent le socle caché du système européen de la parenté et de l'alliance sur lequel repose une partie émergée, " consciente » mais tronquée et transcrite dans le droit canonique, de ce système.

La manière dont le phénomène s'exprime à la fin du Moyen Âge et pendant la première période moderne doit être rattachée, une fois encore, à l'affirmation, partout et de manière progressive dans toutes les classes de la société, entre les XII $-\mathrm{XIII}{ }^{\mathrm{e}}$ et $\mathrm{XIV}^{\mathrm{e}}-\mathrm{XVI} \mathrm{I}^{\mathrm{e}}$ siècles suivant les régions, d'un système onomastique strictement patrilinéaire ${ }^{14}$. La transmission d'un nom de famille fixe et invariable à l'ensemble de la descendance masculine a constitué l'instrument permettant d'individualiser et de positionner globalement, puis dans leurs ramifications internes respectives, les différents groupes familiaux échangeurs entre eux. L'«interdit » d'alliance dans la parenté du père et dans celles des mères est consubstantiel à l'affirmation du nouveau système onomastique qui traduit une révolution sociale et culturelle de portée considérable.

14. Ce problème a fait l'objet, ces dernières années, de recherches précises de la part des historiens médiévistes. Je me limite ici à citer les travaux dirigés pat Monique Bourin \& Pascal Chareille (19891995). Pendant la période post-carolingienne, du IX ${ }^{\mathrm{e}}$ au XI $\mathrm{X}^{\mathrm{e}}-\mathrm{XII}^{\mathrm{e}}$ siècle, nous pouvons dire, en simplifiant un peu les choses, que les seuls «noms " fixes sont ceux qui se rattachent à une terre, c'est-à-dire à une circonscription territoriale comportant généralement l'exercice de fonctions administratives et judiciaires. Ce nom suit celui qui transmet le domaine, qu'il s'agisse d'un homme ou d'une femme. 
La comparaison avec d'autres sociétés non européennes exprimant des règles d'échanges semblables ou voisines, ou encore avec les systèmes de type Crow-Omaha, ne peut être entreprise ici. Je me limite à évoquer le cas de Sarhua et de Vicos, deux communautés des Andes péruviennes étudiées par John Earls (1971) et qui ont également retenu l'attention de Françoise Héritier (1981). Dans les deux sociétés, les groupes se définissent de manière patrilinéaire, mais dans le premier cas nous avons affaire à deux moitiés endogames et non localisées composées chacune d'unités exogames (une situation que nous pouvons rapprocher de celle de Manduria), dans le second à de véritables groupes lignagers géographiquement localisés et exogames (une situation assez semblable à celle rencontrée dans les régions internes de la Campanie - le système des Casa-ou, comme nous le verrons ensuite, de Guillestre et Champoléon). Dans les deux cas, on ne prend pas conjoint dans le groupe de son père (son unité ou son lignage) ni dans celui de sa mère. John Earls montre comment l'existence de quatre groupes exogames suffit, théoriquement, pour que tous les échanges matrimoniaux respectent les règles. Mais l'anthropologue développe sa logique et ses modèles en s'appuyant sur des données qui ne concernent que le présent immédiat; il retient uniquement l'interdit sur le groupe de la mère et, si le modèle abstrait que Earls en déduit apparaît pertinent, il suffit cependant de considérer la diachronie et le pluriel, c'est-à-dire l'ensemble des groupes des mères, pour découvrir et expliquer, à travers le classement progressif des lignées en épousables et non épousables, un mode de fonctionnement effectif, qui se moule sur l'histoire particulière de chaque descendance. L'histoire modèle, donne forme à la structure et non l'inverse, et cette irruption de l'histoire nous invite alors à reconsidérer certaines caractéristiques de la démarche méthodologique de l'anthropologie (l'approche dans la synchronie) et des concepts qui en découlent.

Il convient de souligner une conséquence importante, de nature économique, de l'empêchement dans les lignages des mères. À la fin du $\mathrm{XVII}^{\mathrm{e}}$ siècle, Francesco Dimitri ne peut pas, selon le droit canonique, prendre épouse parmi toutes ses cousines jusqu'au $4^{\text {e }}$ degré, mais il doit aussi éviter, comme je l'ai déjà dit, toutes les filles Dimitri (de son propre lignage) et toutes les filles Pecorara, Gennara, Micella 1, De Strati, etc. (des lignages de ses mères). Ce ne sont pas 5,10 ou 20 personnes qui lui sont interdites, ce sont plusieurs dizaines, pratiquement un quart du village... À chaque génération, la lignée doit renouveler ses alliances, chercher plus loin, et la difficulté sera d'autant plus grande que la mémoire de la famille sera longue. Le système pousse à l'exogamie qui est aussi une 
exogamie de plus en plus ouverte et large des dots et des biens. La thèse traditionnelle encore récemment avancée par Maurice Godelier, selon laquelle l'accélération des échanges économiques aurait entraîné une désarticulation profonde des rapports de parenté et d'alliance qui n'obéiraient plus, dès lors, qu'à des motivations d'ordre politico-financier, ne résiste pas à l'examen des faits. Nous sommes plutôt en droit de nous demander si les termes du rapport ne doivent pas être, en partie, inversés : n'est-ce pas le système général des échanges matrimoniaux tel que nous le voyons fonctionner jusqu'à la fin du XVII siècle qui a entraîné une accélération considérable des échanges économiques?

Dans un tel système, la femme établit une relation d'exclusion entre la lignée masculine qu'elle engendre et toutes les personnes portant son propre nom, c'est-à-dire son lignage masculin d'origine. Le système repose sur une dialectique entre lignée et «lignage » et non entre lignée et lignée, comme on l'affirme parfois (Rheubottom 2000) ou comme on voudrait en faire une caractéristique essentielle du système occidental (Goody 1983). Le système chrétien occidental ne peut être analysé sur la base d'oppositions rigides entre filiation unilinéaire et cognatique, entre lignage et parentèle, entre segmentation et non segmentation... Il pose plutôt, dans les modalités de son déroulement diachronique, le problème d'une éventuelle révision de ces concepts.

Le rôle de pont de la femme, comme cela ressort de nos données et se comprend par ailleurs aisément, cesse immédiatement dans les descendances féminines : une fille de femme n'impose pas à ses enfants d'interdit sur le lignage de sa mère; seuls les hommes peuvent transmettre, en même temps que le nom de famille, un interdit sans cesse répété sur le père, puis sur le père du père et sur les parentés masculines de leurs épouses respectives. Ego ne peut donc s'adresser ni au lignage de sa mère ni à celui de sa grand-mère paternelle, mais il peut, sans problème, interpeller celui de sa grand-mère maternelle. Le sang des mères ne compte que s'il est transmis par les hommes. Le déséquilibre des rôles est patent mais il est une condition nécessaire au fonctionnement du système. Le schéma de bouclage $\mathrm{n}^{\circ} 2$ décrit précédemment, dans lequel Ego évite de nouer une alliance dans le "lignage " de son père en s'adressant à celui de la mère, n'est donc pas recevable. Ego ne peut pas non plus se tourner du côté de sa grand-mère paternelle (bouclage $\mathrm{n}^{\circ} 3$ avec un seul passage féminin, cf. page suivante). Il ne peut donc regarder que vers le lignage de la mère de sa mère, c'est-àdire la grand-mère maternelle, ce qui débouche sur un circuit comprenant au minimum deux passages féminins (bouclage $\mathrm{n}^{\circ} 4$ ). Si la règle est bien suivie en ces termes (passage par la grand-mère maternelle), elle débouche sur des bouclages caractérisés par une première ligne de descendance 
féminine et par une seconde masculine. Mais ce n'est qu'un cas de figure possible: le passage par la grand-mère maternelle est effectivement pratiqué mais, dans les faits, les deux femmes - ou plus - peuvent se positionner indifféremment à tous les niveaux du circuit d'alliance. La parenté des deux conjoints peut, par exemple, passer par leur mère respective.

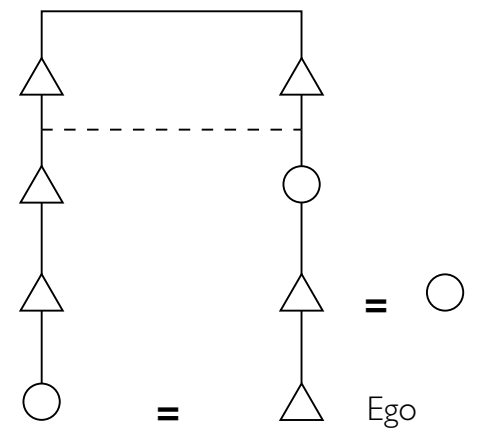

Bouclage $n^{\circ} 3$

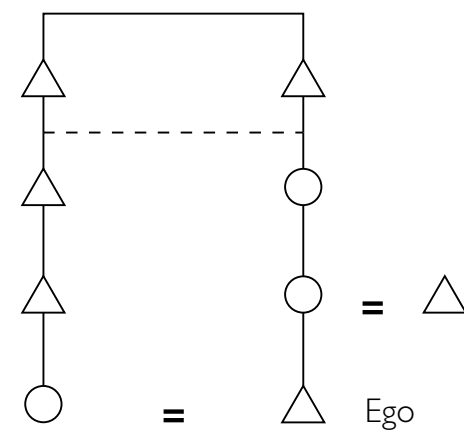

Bouclage $n^{\circ} 4$

Ce qui semble nécessaire, dans tous les cas, c'est un "chapeautage» consanguin qui se situe toujours, au minimum, au $3^{\mathrm{e}}$ degré (ligne en tirets). En effet, des mariages plus proches, au deuxième degré, ne sont possibles ni avec la cousine parallèle patrilatérale (lignage du père) ni avec la cousine croisée matrilatérale (lignage de la mère). Si Ego cherche une alliance parmi les enfants d'une sœur du père (cousine croisée patrilatérale), il s'adresse effectivement à des personnes qui sont sorties des lignages de ses propres géniteurs. L'inverse, cependant, n'est pas vrai : en épousant Ego, la cousine croisée patrilatérale va se marier dans le lignage de sa propre mère et, par un effet normal de réversibilité de la règle, une telle alliance s'avère impossible.

Notre système occidental se serait-il contenté d'ajouter un degré supplémentaire à ce qui semble une conséquence structurale de l'éviction des lignages du père et de la mère ? Notons que le $3^{\text {e }}$ degré canonique (ou le $7^{\text {e }}$ degré civil) a toujours constitué la clé de voûte fondamentale du système chrétien, en Occident comme dans l'Orient byzantin, et que l'ajout, par l'Église romaine, d'un $4^{\mathrm{e}}$ degré peut s'expliquer par des raisons historiques liées aux contacts avec les populations barbares et à l'adoption d'un nouveau comput. Une recherche en cours à partir d'un grand nombre de demandes de dispenses pour consanguinité au XVI ${ }^{\mathrm{e}}-\mathrm{XVIII}{ }^{\mathrm{e}}$ siècle montre cependant que les mariages au $3^{\mathrm{e}}$ degré présentent encore une proportion 
importante de chaînes de parenté incluant un seul passage féminin. Le $4^{\mathrm{e}}$ degré, en multipliant les occurrences (6 passages au lieu de 4 ) s'est peutêtre révélé, tout simplement, plus apte à un meilleur respect des règles. En tout état de cause, c'est bien ainsi que, concrètement, les choses se passent.

Il existe pourtant une possibilité de mariage "proche " qui respecte les empêchements dans le même nom, celle entre cousins parallèles matrilatéraux :

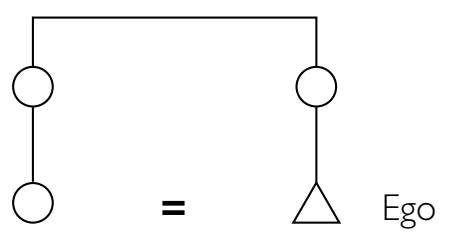

Dans ce cas, ni Ego ni son épouse ne se marient dans les lignages de leurs pères et mères respectifs, mais cela suppose que la relation d'alliance l'emporte décidément sur celle de parenté (les deux sœurs) et on bascule alors dans un système " arabe inversé ", construit sur l'union préférentielle avec une cousine parallèle matrilinéaire, ce qui n'est certainement pas le but recherché. On ne trouve guère d'exemple de société patrilinéaire ayant évolué vers une organisation de type matrilinéaire. Mais une telle solution est théoriquement et concrètement possible et l'interdit de consanguinité jusqu'au $4^{\mathrm{e}}$ degré apparaît aussi comme un instrument pour imposer une symétrie dans les passages par les hommes et par les femmes et pour prévenir, par là, une éventuelle dérive vers des relations " courtes " par voie exclusivement féminine et vers un système matrilinéaire. Les conceptions culturelles et médicales sur ce problème sont parfois explicites : au milieu du XIX siècle encore, un médecin milanais considérait les mariages entre cousins parallèles matrilatéraux beaucoup plus dangereux pour la santé que ceux entre cousins croisés ou cousins parallèles patrilatéraux. Ils présentaient aussi le défaut majeur d'unir des personnes issues de deux femmes, donc de deux paternités « incertaines» (Merzario 1981).

Résumons-nous : en 1215, le concile du Latran fixe définitivement l'aire de parenté interdite au $4^{\mathrm{e}}$ degré canonique, aussi bien dans la consanguinité (en ligne masculine comme en ligne féminine) que dans l'affinité. Il met fin à de longs et vieux débats particulièrement vifs dans le Saint-Empire, entre tenants d'empêchements pesant sur "toute » la parenté et tenants d'empêchements plus limités (Corbet 2001). Les seconds semblent l'avoir emporté et, à travers eux, l'historiographie et l'anthropologie de la parenté occidentale n'ont d'yeux que pour les quatre degrés interdits et fondent sur eux leurs approches et leurs raisonnements. Pourtant, dès les débuts du XIII ${ }^{e}$ siècle, 
un autre mouvement est à l'œuvre, qui s'impose progressivement et bientôt triomphe; à la fin du XV et au début du XVI siècle, il est devenu une règle de comportement quasi universelle : c'est l'onomastique du double nom (nom et prénom) avec transmission indéfinie d'un nom de famille dans les descendances patrilinéaires. Ce nouveau mode de définition des identités porte avec lui des comportements, des « interdits » dans les parentés masculines du père et des mères qui se surajoutent à ceux officiels de l'Église et les complètent; ils marquent la fin des phénomènes de segmentation qui ne subsistent, aux XVI ${ }^{\mathrm{e}}$ et $\mathrm{XVII}^{\mathrm{e}}$ siècles, qu'à l'état résiduel - comme nous le verrons par la suite avec les Cibot de Limoges ou Fégréac -, délimitent des groupes échangeurs, classent les lignées, orientent les alliances.

Si nous acceptons un tel raisonnement qui permet d'expliquer un aspect des modalités d'extension des interdits dans la consanguinité, nous laissons cependant dans l'ombre un autre problème majeur, celui de l'affinité (Héritier 1994). Dans les sociétés chrétiennes occidentales, les deux choses ont toujours été étroitement liées et cela dans des aires d'ampleurs équivalentes : après 1215 , l'interdit jusqu'au $4^{\mathrm{e}}$ degré de consanguinité trouve son correspondant dans l'interdit jusqu'au $4^{\text {e }}$ degré d'affinité. Ce dernier élément élargit ultérieurement le champ des conjoints proscrits mais semble, quant à la logique même du système, inutile : on ne voit pas pourquoi un homme ayant épousé une femme qui n'est du nom ni de son père ni de ses mères et s'en trouve éloignée de plus de quatre degrés de parenté ne peut pas, devenu veuf, s'unir à la sœur de cette femme qui respecte exactement les mêmes conditions. La définition de l'affinité sous-entend, en réalité, celle de l'identité des germains (ensemble des frères et sœurs) et c'est à travers une modification de la notion d'affinité que le christianisme a posé les bases d'un nouveau système - pouvant se décliner de différentes manières - de parenté et d'alliance (Barry 2008). Dans le monde romain antique, les interdits dans l'affinité ne touchent que des alliés de la sphère conjugale de la famille : Ego ne peut pas épouser sa belle-mère ou sa bellefille. Mais il peut épouser sa belle-sœur (dans les deux sens du terme, c'està-dire la sœur de sa femme ou l'épouse de son frère), ce qui signifie deux choses: qu'un frère ou une sœur n'est pas identique à un autre frère ou sœur et que l'affinité créée par le mariage n'englobe pas les germains d'alliés. Le lévirat et le sororat sont légaux et pratiqués (Moreau 2002). C'est cela que le christianisme refuse. Saint Basile, dans une lettre célèbre à Diodore écrite vers 373, en avait clairement exposé les raisons : "Qu'est-ce qui pourrait avoir plus d'affinité avec un homme que sa femme, ou plutôt que sa chair? En effet ils ne sont plus deux chairs mais une seule. Voilà pourquoi la sœur de la femme passe par elle à l'affinité avec l'homme [...]. Il [l'homme] n'épousera pas une sœur de sa femme parce qu'il ne peut 
pas épouser sa propre sœur" (Basile de Césarée 1961). La femme et sa sœur sont présentées comme des êtres, des «substances" identiques (Héritier 1994), d'où il découle que les germains d'alliés sont perçus comme des affins. Le lévirat et le sororat sont vivement réprouvés et c'est d'abord contre eux que la nouvelle religion, encore persécutée, se dresse (concile d'Elvire, fin III--début IV siècle) avant que les nouveaux empereurs chrétiens ne les interdisent définitivement (édit de Constance II, 355).

Proscrire le lévirat et le sororat, c'est signifier qu'un frère est identique à son frère, une sœur identique à sa sœur. Le raisonnement met en marche un enchaînement extensible à l'infini, aussi bien dans le champ de l'affinité que dans celui de la consanguinité : si la sœur de mon épouse/sœur est ma propre sœur, alors mon frère qui m'est semblable est aussi son frère et il ne peut s'unir à elle, ce qu'affirme encore avec force le concile in Trullo (691). Mais, si les germains sont semblables, leurs enfants le sont aussi et ne peuvent s'unir entre eux. L'interdit d'alliance entre cousins germains ( $4^{\mathrm{e}}$ degré romain) suit donc, très «logiquement ", à la fin du IV siècle (code de Théodose; l'interdit, maintenu en Occident sera, pour un temps, abrogé en Orient), celui concernant le lévirat et le sororat. Tous les types de cousins germains (parallèles et croisés) sont concernés ce qui signifie que tous les couples de germains (frère-frère, sœur-sœur, frèresœur) sont considérés comme identiques et donc que la différence de sexe n'introduit pas une différence d'identité. Le seul problème que soulève ce raisonnement est de savoir quand s'arrête le processus d'identification. C'est ce dont les Églises orientale et occidentale ont débattu pendant des siècles. Les empêchements canoniques "officiels" imposés par l'Église catholique, ne sont que l'une des dimensions de cette correspondance des chairs. Dans la pratique, comme nous l'avons vu, les relations d'échanges activent d'autres "empêchements" souvent non dits, plus amples ou plus brefs suivant les lignes de filiation (sans limite dans les masculines, s'interrompant dès la fille de la mère dans les féminines). Une question, dès lors, reste en suspend: comment et quand ces différentes pratiques se sont-elles mises en place? Découlent-elles toutes des nouvelles définitions de rapports de parenté et d'alliance imposées par le christianisme ou reprennent-elles, en partie, certains comportements plus anciens?

Retenons ici un seul aspect, essentiel : l'affinité qui s'étend sur les germains d'alliés et la consanguinité qui frappe les descendants de ces mêmes germains se justifient mutuellement. Les parents jusqu'au $4^{\mathrm{e}}$ degré de l'épouse d'Ego sont inévitablement des affins parmi lesquels il ne peut choisir une nouvelle femme. S’il le faisait, la consanguinité n'aurait plus de fondement et ses enfants (d'Ego) pourraient se marier avec les enfants des sœurs ou des frères de son épouse. 
Tout cela est si vrai que le «système chrétien occidental » entre dans une crise profonde qui débouchera sur nos réalités actuelles, lorsque certains États réformés et surtout les codes civils de la fin du XVIII ${ }^{\mathrm{e}}$ et du début du XIX siècle (Autriche, Prusse, France, etc.) légalisent - avec parfois des retours en arrière temporaires - à nouveau le lévirat et le sororat. La nécessité et les implications d'une telle mesure soulèvent souvent de vifs et longs débats: la Grande-Bretagne discute pendant tout le XIX ${ }^{e}$ siècle sur le problème du lévirat et du sororat et la littérature produite sur le sujet est immense. Partout cependant, la légalisation s'accompagne, parallèlement, d'un retour à des interdits de consanguinité limités ne portant que sur des degrés très proches. Les germains sont redevenus des individus à part entière et la "solidarité " matrimoniale qui les liait, se rompt (Delille 2001). Une sœur n'est plus semblable à une sœur et les enfants issus de ces êtres différents pourront, éventuellement, se marier entre eux ; inversement, ils pourront s'adresser à des "étrangers " sans être tenus à « boucler " de précédentes alliances au-delà des interdits canoniques. Le très proche et le très lointain s'appellent et se justifient mutuellement; ils caractérisent la situation nouvelle des XVIII et ${ }^{\mathrm{e}} \mathrm{XIX}^{\mathrm{e}}$ siècles.

Ces considérations peuvent sembler abstraites et a-historiques. En réalité, c'est en partant de l'analyse précise de tels mécanismes, de leur présence ou absence aux différentes périodes historiques, des règles de droit qui ont pu les concerner et les modifier, mais aussi des écarts parfois considérables qui ont pu exister entre les appareils législatifs et les comportements réels, que l'on peut entrevoir les évolutions et les transformations qui ont marqué, sur le plan de la parenté et de l'alliance, le monde européen occidental. C'est par-là que l'on peut comprendre le passage du système romain antique, construit, sous l'Empire, sur des pratiques extrêmes : celle, d'un côté, d'une exogamie apparemment très large (Veyne 1978) et, de l'autre, de mariages consanguins ou affins très proches (Syme 1986 ; Corbier 1990, 1994); c'est par-là, de la même manière, que l'on peut comprendre comment et pourquoi notre système chrétien est entré, au cours des XVIII ${ }^{e}$ et XIX siècles, dans une crise irréversible et a donné naissance à notre système contemporain.

\section{Les jeux de l'échange}

Une lignée patrilinéaire directe rejette tous les anciens «lignages» alliés dans le groupe des non épousables et doit, à chaque nouvelle génération, trouver de nouveaux partenaires. On pourrait en déduire que ce système débouche sur une exogamie toujours plus large et incontrôlée, sur une «turbulence permanente "selon l'expression de Claude Lévi-Strauss. 
Il n'en est rien. Comme nous l'avons vu dès notre première analyse à partir de l'exemple des Agostina, une alliance ne peut être répliquée en ligne directe, mais elle peut l'être dans les lignes collatérales. Le schéma " classique " d'une telle réplication est celui d'une union reprise à la génération suivante par l'alliance entre un neveu et une nièce de ce premier couple :

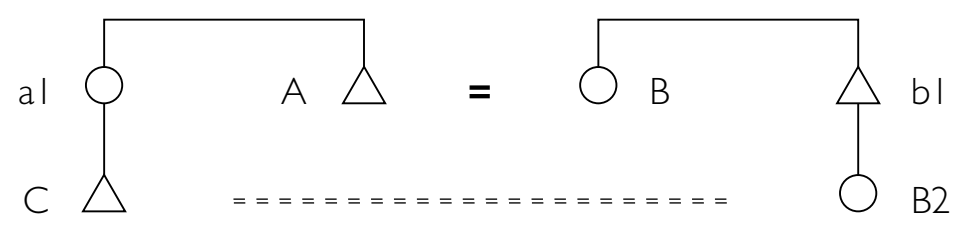

Mariages oncle-neveu avec tante-nièce

Nous pouvons avoir également des unions oncle-nièce avec tante-neveu dans lesquelles le neveu comme la nièce peuvent être indifféremment de frère ou de sœur. Le but de ces jeux dans la collatéralité est de répliquer ou relancer les alliances tout en évitant les interdits, écrits ou non, concernant les lignées directes et les consanguins ou affins jusqu'au $4^{\mathrm{e}}$ degré. Il faut, pour cela, que les lignées d'origine concernées ne présentent pas de parenté proche. Si dans notre schéma précédent, al et b1 avaient épousé un frère et sa sœur, B2 et $\mathrm{C}$ seraient alors cousins au $2^{\text {e }}$ degré, et B se serait mariée dans le «lignage» de sa mère.

À partir de cet échange type oncle-neveu/tante-nièce, différentes interprétations et différentes constructions de parcours d'échanges sont possibles en jouant soit sur la profondeur générationnelle, soit sur les lignes de filiation.

Les choses peuvent se dérouler dans un même espace temporel: A épouse $\mathrm{B}$ qui retourne épouser $\mathrm{A}$, ce qui correspond à un échange de sœurs ou de deux frères avec deux sœurs ou encore de cousines. Cela est possible parce qu'un consanguin proche de même sexe (un frère d'Ego) ou de sexe différent (une sœur d'Ego) peut renouveler l'alliance d'Ego, ce qui est la caractéristique d'un système complexe d'alliance (Héritier 1981) et, comme nous l'avons déjà relevé, différencie fondamentalement le système chrétien occidental du système chrétien oriental-orthodoxe ${ }^{15}$.

15. Dans le système chrétien orthodoxe, l'impossibilité de redoubler l'alliance antérieure d'un consanguin proche découle d'une conception différente de l'affinité: lorsque A épouse B, tous les frères et sœurs de A se retrouvent affins des frères et sœurs de B et ne peuvent donc se marier avec eux. 
Si l'on ajoute à ce schéma un passage supplémentaire, nous aurons A qui épouse B qui épouse $C$ qui épouse A..., c'est-à-dire un mécanisme traditionnel d'échange généralisé. C'est ce que fait Domitio Reggi, originaire d'Arnesano en Terre d'Otrante, qui vient s'installer à Manduria, probablement grâce à son mariage avec Ambrosina Puglia, fille d'Urso Puglia et de Montagna Mera, vers 1555-1560. Le destin de ce couple et de sa descendance sera bref: un fils unique, Geronimo, lui-même père de deux filles, Sarra et Ambrosina. La simplicité de ce développement généalogique, la pauvreté et l'isolement de la famille ne permettent pas la mise en place d'un jeu complexe d'échanges entre lignées alternées. Cependant, Geronimo Reggi et ses filles ne se marient pas dans le lignage de leur père - qui n'existe pas -, ni dans ceux de leurs mères. Ils mettent en place, à travers leurs alliés du côté féminin, des échanges courts, de type généralisé ou à travers un remariage :

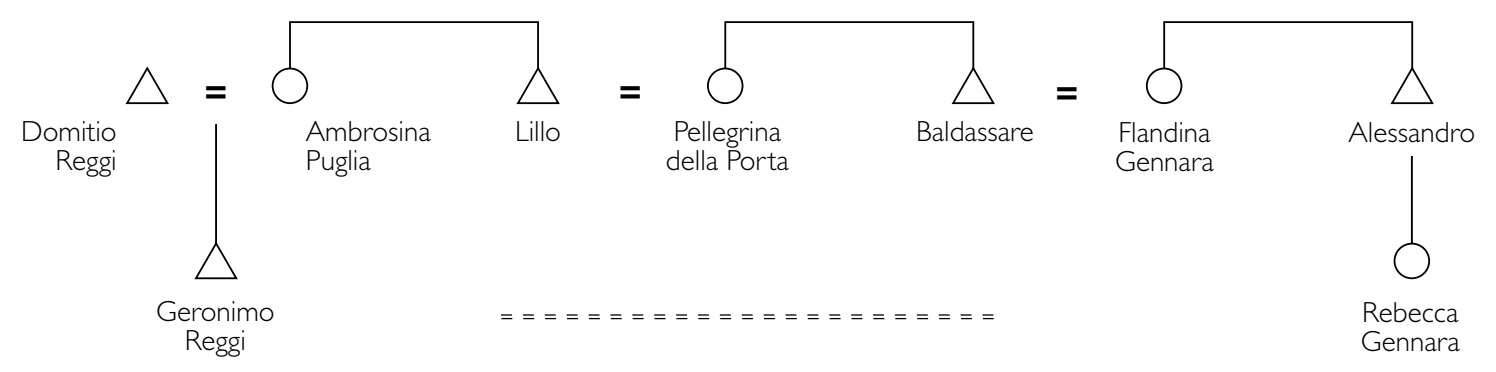

Échange généralisé. Manduria, $\left.x v\right|^{e}$ siècle

Rebecca Gennara s'unit, en secondes noces, à Stefano Micella et donne sa fille, Ambrosina Reggi, à Gabriele Micella, fils d'un premier lit de Stefano. En épousant Geronimo Quarta, Sarra Reggi, autre fille de Geronimo, réalise, de son côté, un bouclage au $5^{\mathrm{e}} / 6^{\mathrm{e}}$ degré remontant à Reminia et Alfonso Gennara. Très vite réinsérés dans le cadre de mécanismes plus amples, les échanges courts ne restent tels que lorsqu'il y a interruption rapide et répétée des lignées. Ce type de situation est fréquent au niveau des familles isolées qui ne parviennent pas à se développer et à s'enraciner en tant que "lignages». Les pauvres, les migrants, les cadets de famille expulsés des Maisons sont les premiers concernés, mais d'autres familles peuvent également, comme le montrent des travaux récents sur la bourgeoisie parisienne des XVI et $\mathrm{XVII}$ siècles (Hamon 1999; Chatelain 2008), avoir recours à ce mécanisme souple et ouvert à des fins d'ascension sociale. L'échange généralisé se suffit alors à lui-même; le jeu se renouvelle constamment au cours des 
générations, offrant l'image d'une société très fluide. De tels critères sont peut-être déjà dominants dans la société anglaise des XVI et XVII ${ }^{e}$ siècles. Une question reste alors en suspend: ces mécanismes déployés dans un espace générationnel court, restent-ils "coiffés " par des bouclages consanguins plus ou moins systématiques?

Si les passages dans la collatéralité et dans l'affinité se répètent au cours des générations successives, ils peuvent donner lieu à des ré-enchaînements réguliers d'alliances du type de ceux décrits par Martine Segalen (1985) pour la Bretagne des XVIII e et XIX siècles et se présenter, en fonction des différents contextes familiaux (multiplication ou extinction de branches collatérales, enfants nés de lits différents, etc.), sous des formes très diverses. Lorsque les relations s'effectuent exclusivement entre lignées patrilinéaires de deux «lignages " différents, on débouche sur un mécanisme d'échange entre lignées alternées. Les alliances sont constamment reprises avec des époux-épouses choisis dans des lignées différentes des précédentes. J'ai déjà eu l'occasion de décrire et d'illustrer les caractéristiques principales d'un tel système en d'autres lieux (Delille 2000) et de montrer qu'il se retrouve partout en Europe occidentale, de l'Italie à l'Espagne, de la France du Sud et du Nord aux Pays-Bas et à l'Allemagne, et représente des proportions souvent élevées de l'ensemble des unions... Pour relever des « exceptions » d'ailleurs partielles, il faut, encore une fois, se tourner vers l'Angleterre et l'Europe du Nord.

Dans le cas de Manduria, il est possible de préciser l'importance de ces échanges par rapport à l'ensemble des mariages effectivement célébrés. Pour la période du début du XVI ${ }^{\mathrm{e}}$ au début du XVIII ${ }^{\mathrm{e}}$ siècle, les unions renouvelées dans les lignées collatérales masculines des deux premiers époux sont, chez les D’Agostina, au nombre de 31 sur un total général de 132 , soit $23,48 \%$. Certaines se déploient sur de longues périodes temporelles et intéressent un grand nombre de lignées: les Mera se représentent 7 fois, les Pasanisa 4 fois sur plus d'un siècle. Chez les D’Alemma, nous avons 7 échanges en lignées alternées avec les Piccinna, 6 avec les Ricchiuta, 6 avec les Micella, 4 avec les Mera.

Pour les D’Agostina, il faut ajouter 5 échanges de sœurs et 9 échanges du type deux frères épousent deux sœurs, pour un total de 29 mariages. Ces échanges "organisés " représentent déjà, à eux seuls, 60 cas et $45,4 \%$ des alliances. Chez les D'Alemma, sur 162 mariages, 60 relèvent d'échanges entre lignées alternées masculines et 23 d'échanges directs, soit une proportion de 51,23\%. Si nous considérons que les circuits passant par les femmes n'apparaissent pas directement sur nos généalogies mais sont fort nombreux (Delille 2003 : 226), ce sont au minimum $70 \%$ ou plus des 
mariages qui obéissent à des règles d'échange dans la collatéralité, en particulier entre lignées alternées. Ce sont des taux considérables qui ne laissent aucun doute sur la prégnance des mécanismes structuraux dans nos sociétés « cognatiques» occidentales continentales, jusqu'au XVIII siècle. "Les jeux de l'amour et du hasard ", c'est pour la littérature ou pour plus tard!

Dans le Boulonnais, les proportions semblent un peu moins élevées, mais nos généalogies sont aussi moins précises et moins complètes. Chez les Routtier, sur 169 mariages, 27 se présentent sous forme d'échanges entre lignées alternées et 12 sous forme d'échanges directs, soit 23,07\%. Chez les Brunet, les chiffres sont de 17 sur 63 (26,98\%) et chez les De Bonningue de 38 sur 107 (35,51\%). Les pourcentages restent donc importants et il faudrait tenir compte d'autres mécanismes d'organisation des échanges plus fréquents qu’à Manduria (ceux, en particulier, à travers les veuves et les remariages).

Les mêmes mécanismes d'échanges entre lignées alternées et d'échanges directs se retrouvent partout ailleurs, à Guillestre, à Champoléon, à Fégréac, à Verviers, dans des proportions variables mais toujours élevées.

Précisons rapidement quelques aspects du fonctionnement de ces échanges entre lignées alternées et quelques-uns des problèmes qu’ils soulèvent sur le plan de l'interprétation théorique. Le schéma "classique " veut, qu'après un premier échange (par exemple, un frère et une sœur épousant une sœur et un frère d'un autre lignage), les deux lignées descendantes directes n'activent plus de relations entre elles pendant trois ou quatre générations. Cependant, une lignée collatérale de l'une peut s'adresser à une lignée collatérale de l'autre pour répliquer la première union sans enfreindre les interdits canoniques. Une fois passées ces 3-4 générations, les lignées initiales peuvent célébrer de nouveaux mariages entre elles, de manière à "relancer " le système. Nous aurons donc, dans les descendances patrilinéaires, alliance soit dans le lignage d'une mère (l'arrière ou l'arrière arrière-grand-mère, si au départ il y a eu échange de sœurs) soit dans celui du père (si les échanges se font à l'intérieur d'un même groupe très vaste comme les Cibot ou les Ysenburg). Ces systèmes, nous le verrons, existent: c'est, dans le premier cas, celui, au moins partiellement, de l'Ouest français, dans le second, celui des Cibot de Limoges ou des villages de haute montagne comme Champoléon. Ils supposent néanmoins la continuité de mécanismes de segmentation qui, aux XVI ${ }^{\mathrm{e}}$ et XVII ${ }^{\mathrm{e}}$ siècles, apparaissent globalement marginaux. Le système dominant exclut les segmentations et les mariages dans le même nom du père ou des mères. Il impose, dès lors, de nouvelles limites draconiennes à la continuité des relations entre deux lignages. Si les alliances ne peuvent plus être relancées, en ligne directe, toutes les quatre ou cinq générations, 
leur réplication devient alors strictement tributaire de l'expansion démographique des lignages. S'il y a, à chaque génération, apparition de nouvelles lignées collatérales, les deux groupes pourront planifier de nouveaux mariages; dans le cas contraire, les relations cesseront. Un très grand lignage pourra retarder cette dernière échéance en recherchant dans le vaste groupe patrilinéaire de son allié traditionnel des lignées épousables, c'est-à-dire ne présentant pas d'ancêtres maternelles provenant de ses rangs, mais cet avantage a aussi un inconvénient qui devient probablement, au cours des XV et XVI ${ }^{e}$ siècles, majeur : il contraint à s'adresser à des lignées de condition sociale différente et donc accentue les disparités et accélère ultérieurement la circulation des biens. C'est peut-être pour pallier ces problèmes que les classes possédantes et dirigeantes retournent progressivement, un peu partout en Europe, à partir de la fin du $\mathrm{XVI}^{\mathrm{e}}$ siècle, à des mécanismes de primogéniture et de célibat des cadets.

Un même système reposant sur un certain nombre de "règles " centrales fondamentales (pas de mariage dans les mêmes noms que le père et les mères, éventuelles reprises d'alliances à travers les collatéraux) peut en réalité se décliner suivant des modes très différents et déboucher, dans des temps longs, sur d'imposantes « constructions » impliquant la cohésion de toutes ou d'une grande partie des lignées - généralement masculines descendant d'un même ancêtre commun, ou se limiter, au contraire, à de simples échanges de type généralisé sur une profondeur générationnelle limitée appelés ensuite à être constamment renouvelés.

De manière générale, une des questions importantes qui se pose me semble donc être la suivante: pourquoi, suivant les pays ou les régions, suivant les "classes" sociales, suivant les familles, voire suivant les choix des individus, voyons-nous se dessiner une construction plus ou moins éphémère ou durable - mais toujours " organisée » - plutôt qu'une autre?

\section{Des bouclages systématiques}

Toute lignée directe cumule, au cours des générations, les interdits dans les noms des mères et doit renouveler constamment ses alliances. Le système pousse donc à une exogamie toujours plus large et, sans un mécanisme permettant des recentrages réguliers, des "retours" sur soi, il éclaterait dans tous les sens, ce qu'il finira d'ailleurs par faire. Les communautés villageoises souvent fortement endogames, que les historiens de l'Europe continentale rencontrent fréquemment encore aux XVI et $\mathrm{XVII}^{\mathrm{e}}$ siècles, ne seraient que des lieux de passage sans de tels retours constants. Les «bouclages» ne sont pas, je pense, de simples sous-produits 
des ré-enchaînements d'alliances, ils en sont la condition. Mon but est de montrer que ces bouclages, dont l'étude pose par ailleurs de difficiles problèmes de sources, relèvent, au moins jusqu'au milieu du XVIII ${ }^{\mathrm{e}}$ siècle, d'une pratique normale découlant du fait que les alliances sont orientées. Le classement des lignées en épousables et non épousables guide les reprises ou les réplications d'alliances et conduit, pour relancer le système, à s'adresser au lignage de la mère de la mère ou, plus généralement, à passer au minimum par deux maillons féminins. Les généalogies de Manduria comme celles du Boulonnais et de nombreux autres villages ou groupes sociaux européens offrent de nombreux exemples de tels bouclages.

À Manduria, Francesco D’Agostina, fils aîné de Paolo, s'unit, dans les années 1560, à Cipriana Pasanisa. La grand-mère maternelle de cette dernière est une Palmera, si bien que les alliances nouées avec des Palmera à la génération des enfants et petits-enfants de Francesco (Locente et Ursina D’Agostina avec Donato et Biondo Palmera, puis Vittorio D’Agostina avec Lidia Palmera) s'avèrent toutes consanguines au $5^{\mathrm{e}}$ ou, dans le cas de Vittorio, au $6^{\text {e }}$ degré. Notons que Locente, Ursina et Vittorio sont tous des cadets. Les choses cependant ne s'arrêtent pas là. Une sœur de Guarino Palmera - le père de Donato et Biondo -, Locente, a été mariée à Cataldo Erario : leur petit-fils, Carlo Erario prendra pour femme Modesta D'Agostina, sœur de Locente et Ursina, soit de nouveau un bouclage au $6^{\text {e }}$ degré remontant aux Palmera. Encore, Perna Palmera, fille du même Guarino et sœur de Lidia Palmera, s'est alliée à Cesare Di Maglie: leur fils, Paolo Di Maglie, prendra pour femme Modea D’Agostina, sœur de Vittorio (l'époux de Lidia), soit encore une consanguinité au $6^{\text {e }}$ degré. Plus tard, une petite-fille de Vittorio, Angela Antonia D’Agostina, épouse un Cazzolla descendant de Soprana Palmera: le mariage se situe au $5^{\text {e }}$ degré si on considère les passages, d'un côté par Soprana Palmera et, de l'autre, par Lidia Palmera, la grand-mère paternelle d'Angela Antonia, mais il est aussi consanguin au $8^{\text {e }}$ degré si on passe par Soprana et, dans l'autre direction, non plus par Lidia mais par Cipriana Pasanisa, ancêtre féminin de la lignée d'Angela Antonia.

D'autres bouclages, très nombreux, nous ramènent à cette Cipriana Pasanisa. Pietro D'Agostina, son arrière-petit-fils, épouse, vers le milieu du $\mathrm{XVII}^{\mathrm{e}}$ siècle, Agata Pantechi. La grand-mère maternelle de Pietro est Flori Pasanisa, fille de Marcello, lui-même frère d'Horatio, ancêtre de Agata Pantechi. Soit un bouclage au $4^{\mathrm{e}} / 5^{\mathrm{e}}$ degré qui passe, cette fois, par la grand-mère maternelle de l'époux. Mais là encore, tout s'enchaîne : le père de Pietro, Francesco D’Agostina, lui aussi aîné de sa fratrie, avait épousé Urania Dimitri, fille de Flori Pasanisa. La grand-mère, paternelle cette fois, 
de Francesco n'est autre que Cipriana Pasanisa. Ces deux femmes nous ramènent à deux frères "ancêtres " de lignée, Dragonetto et Bernardino Pasanisa. Francesco D’Agostina et Urania Dimitri sont ainsi consanguins au $5^{\text {e }}$ degré. Ce bouclage s'encastre sur le précédent, puisque Urania Dimitri est aussi la mère de Pietro D’Agostina; il s'y surajoute aussi : si on passe non plus par Flori Pasanisa mais par Cipriana Pasanisa, l'union entre Pietro D'Agostina et Agata Pantechi est consanguine non plus au $4^{\mathrm{e}} / 5^{\mathrm{e}}$ degré mais au $6^{\mathrm{e}} / 7^{\mathrm{e}}$ degré... (voir schéma 1 , en annexe).

Je pourrais, là encore, continuer à l'infini. Les mêmes constructions se retrouvent dans l'autre lignée des D’Agostina, celle issue de Cicco. Ainsi, par exemple, trois fils et une fille de Giovan Loiso D'Agostina contractent des unions consanguines au $4^{\mathrm{e}}$ degré remontant toutes, à travers la grandmère maternelle, Vittoria Delfina, d'un côté, et la grand-mère maternelle de leurs épouses et époux, Sarra Delfina, de l'autre, au couple de frères " ancêtres ", Antonello et Pascarello Delfino. Le jeu est partout le même et il se retrouve dans toutes les familles de Manduria. J'ai tenté de montrer, dans un autre travail, que les bouclages immédiatement au-delà de l'interdit des quatre degrés sont systématiques (Delille 2003) ${ }^{16}$. Je voudrais souligner ici quelques caractéristiques de ces bouclages qui me paraissent essentielles :

- Le long des générations, les bouclages s'encastrent régulièrement les uns dans les autres et empilent les consanguinités les unes sur les autres. Si l'on excepte les unions célébrées en deçà des degrés interdits qui nécessitent d'une dispense ecclésiastique ou civile, celles au $44^{\mathrm{e}} / 5^{\mathrm{e}}$ reflètent seulement le parcours consanguin le plus court; en remontant encore les filiations et en bifurquant par d'autres chemins, on s'aperçoit que ces mêmes alliances se greffent également sur des cycles plus longs de sept, huit, neuf générations et plus. Les bouclages ne sont donc pas le résultat de recoupements aléatoires le long des générations, mais bien des constructions systématiques répondant à de mêmes lois d'organisation générale des échanges.

- La figure de bouclage à travers la mère de la mère qui est une conséquence structurale de l'interdit d'alliance dans les lignages du père et des mères est fréquente mais non systématique. Des raisons d'ordre démographique peuvent intervenir; surtout, la position dans la chaîne de parenté des deux passages féminins "obligés " peut varier de manière relativement indifférente. Rien n'empêche aussi que le nombre de passages féminins soit supérieur à deux et on peut, à la limite, avoir des chaînes 
entièrement féminines (ce qui est, malgré tout, très rare). Le passage par les femmes a pour conséquence que les frères/sœurs initiaux auxquels ramène le bouclage sont rarement des représentants d'une des lignées masculines d'un des deux époux. Les bouclages mis en évidence chez les D'Agostina conduisent à des couples frères/sœurs de départ parmi les Pasanisa, les Palmera, les Delfina.

Tournons-nous maintenant vers le Boulonnais. Parmi les familles considérées précédemment, beaucoup d'unions sont nouées avec des personnes dont les généalogies familiales n’ont pas été reconstituées. Il est, dès lors, impossible de savoir s'il y a bouclage. En revanche, lorsque les ascendances et les descendances des deux conjoints sont connues, les bouclages apparaissent de manière systématique. Ils se concentrent, comme à Manduria, dans cette aire générationnelle des $4^{\mathrm{e}}-6^{\mathrm{e}}$ degrés de consanguinité. Dans les familles Cugny, Dupont et Hamerel, sur 36 bouclages recensés entre la fin du XVII et le milieu du XVIII ${ }^{\mathrm{e}}$ siècle, 24 soit les deux tiers se situent entre le $4^{\mathrm{e}}$ et le $6^{\mathrm{e}}$ degré, le reste se répartit entre les $2^{\mathrm{e}} / 3^{\mathrm{e}}-3^{\mathrm{e}} / 4^{\mathrm{e}}$ degrés (6 bouclages) et les $6^{\mathrm{e}} / 7^{\mathrm{e}}-7^{\mathrm{e}} / 8^{\mathrm{e}}$ degrés ( 6 bouclages également). Comme à Manduria, nous trouvons des passages à travers la mère de la mère: en 1689, Pierre Dupont épouse Antoinette Routtier ( $6^{\mathrm{e}} / 7^{\mathrm{e}}$ degré) et les deux seuls passages féminins se font à travers la mère de Pierre, Denise Duflos, et la mère de cette dernière, Péronne Routtier. En 1680, Marguerite Routtier convole en justes noces avec Antoine Hamerel $\left(4^{\mathrm{e}} / 5^{\mathrm{e}}\right.$ degré) et le bouclage passe cette fois par la mère (Catherine Dupont) et la grand-mère maternelle (Marie Coze) de l'épouse.

Surtout, comme à Manduria, les bouclages s'encastrent régulièrement les uns dans les autres et les plus courts ( $4^{\mathrm{e}}-5^{\mathrm{e}}$ degrés) sont régulièrement surmontés, en suivant d'autres ascendances, par des bouclages plus longs, au $7^{\mathrm{e}}, 8^{\mathrm{e}}$ ou $9^{\mathrm{e}}$ degré. Sur tous ces points, le schéma 2, en annexe, apparaît explicite.

La comparaison avec Manduria laisse entrevoir certaines différences: dans le Boulonnais, les bouclages en deçà du $4^{\mathrm{e}}$ degré sont plus nombreux et une des deux lignées du bouclage, en partant de l'époux ou de l'épouse, se présente plus fréquemment en succession strictement masculine. Des facteurs d'ordres sociaux peuvent intervenir : familles de laboureurs dans le Boulonnais, familles d'ouvriers agricoles et d'artisans à Manduria. Il pourrait s'agir aussi de particularités plus profondes des systèmes d'échange. Il est, en tout état de cause, trop tôt pour conclure.

Au niveau de communautés ou de groupes locaux, l'étude systématique des bouclages consanguins est souvent difficile car il faut disposer d'ensembles généalogiques considérant toutes les familles et indiquant de 
manière continue et précise la filiation de tous les individus. Il faut, par ailleurs, pouvoir travailler sur la période précédant approximativement les années 1730 , car, après cette date, suivant des chronologies différenciées, les règles d'échanges matrimoniaux se modifient profondément. Dans les cas privilégiés où nous avons pu conduire une telle recherche ou recueillir des données suffisamment précises - à Solofra en Campanie (Delille 1985), à Arles pour les familles de la classe dirigeante locale (Du Roure 1907), à Gannat dans le Bourbonnais (Frémont 1990-1993), à Jezainville en Meurthe-et-Moselle (Wolff 2007), à Verviers en Belgique (Hanquet 1957 ; Le Pas de Sécheval 1990 ; Plouy 1965), à Nerkausen dans la Hesse allemande (Sabean 1997), à Guillestre et à Champoléon dans les HautesAlpes (www.geneanet.org), à Peglio dans les Alpes italiennes (Merzario 1981), à Fégréac dans l'Ouest français (Tables de Fégréac 2006; www.geneanet.org) (avec, dans ce dernier cas comme dans celui des villages de montagne, des particularités sur lesquelles je reviendrai ensuite) -, les bouclages apparaissent comme une réalité profonde et structurante de ce qu'il faut bien appeler un "échange des femmes" ou une "circulation contrôlée des femmes", et confirment les interprétations de Françoise Héritier sur les sociétés complexes (1981). Partout, nous retrouvons les mêmes caractéristiques fondamentales: majorité de bouclages situés entre les $4^{\mathrm{e}}$ et $\sigma^{\mathrm{e}}$ degrés, à la limite ou immédiatement après l'interdit canonique des quatre degrés, bouclages encastrés les uns dans les autres et se cumulant au cours des générations. Ajoutons à cela que les rares unions dans le même nom ou dans le nom d'une mère se situent elles aussi, fréquemment, comme je l'ai signalé, entre le $4^{\mathrm{e}}$ et le $6^{\mathrm{e}}$ degré.

Toutes les raisons sont donc bien réunies pour que, dans le système européen de la parenté, les alliances se bouclent sur elles-mêmes.

\section{Aux marges du système}

Jusqu'à quel point les mécanismes que j'ai tenté de dégager ont-ils valeur générale? Sur le plan documentaire, les choses n'apparaissent pas toujours aussi simples qu'à Manduria ou que dans le Boulonnais. Certaines communautés, comme l'indique le tableau 2 en annexe, présentent des proportions de mariages dans le lignage du père et dans ceux des mères relativement élevées et qui semblent contredire la règle générale.

Le cas de Verviers, apparemment en accord avec les données générales concernant les mariages dans le lignage du père et dans ceux des mères, soulève en réalité un problème que nous avons déjà rencontré. À la fin du $\mathrm{XVI}^{\mathrm{e}}$ et au XVII siècle, le phénomène de segmentation a disparu ou ne se présente plus que de manière épisodique, mais il était, semble-t-il, encore 
très vivant $\mathrm{au} \mathrm{XV}$ et au début $\mathrm{du} \mathrm{XVI}^{\mathrm{e}}$ siècle. Les données recueillies indiquent clairement que nombre de noms de famille ne sont que des «surnoms " de branches détachées de "lignages» plus anciens. Ainsi, les Grosfils auraient donné naissance aux Wilkin qui, à leur tour, auraient donné naissance aux Delle Thour; les Le Rideur seraient issus des Le Jetteur, les Pature des Del Court, etc. De telles pratiques ne doivent pas étonner dans une région où la noblesse s'est longtemps parée du seul nom du fief principal et où, de manière générale, au XIVe-XV siècle encore, l'aîné des garçons prenait le nom du père et le cadet celui de la mère (Xhayet 1997). À Verviers, l'ampleur et la chronologie des transformations qui marquent le passage de ces segmentations continues à une dénomination fixe des descendances masculines restent très floues et ne permettent pas de préciser dans quelle mesure des alliances mettant en présence des personnes de noms différents ne sont pas, en réalité, de type parallèle patrilatéral. Une telle incidence est probablement déjà très limitée à la fin du XVI ${ }^{\mathrm{e}}$ siècle.

À Guillestre, la reprise précoce des mariages internes s'appuie sur le maintien, voire le retour, de mécanismes de segmentation. Ainsi les Brun, qui connaissent une forte croissance démographique au XVII ${ }^{e}$ siècle, se divisent en réalité en plusieurs branches bien identifiées qui se réferent chacune à un ancêtre connu : nous avons ainsi la lignée issue, à la fin du XVI ${ }^{\mathrm{e}}$ siècle, de François Du Villaron Brun, celles, à la fin du XVII siècle, de Jacques De Chanousse Brun, de Jean Des Bruns Brun ou de Jacques De La Frairie Brun. Cette dernière, qui continue jusqu'au XIX siècle, se fragmente rapidement dans les Du Cros Brun, les Du Coin Brun, les Du Quartier du Roy Brun, les De l'Église Brun, les De Saint Crépin Brun, etc. Tous les déplacements, tous les changements de résidences sont immédiatement intégrés au nom de famille, placés comme témoins d'une future nouvelle segmentation du lignage. Le lieu fait la lignée et les surnoms de lieu ne sont attribués qu'aux hommes. Les femmes doivent se contenter de références plus prosaïques : Marie la Gauragne, Marguerite la Boiteuse...

Mais Guillestre est un bourg de vallée et un lieu de transit important, et ces mécanismes restent marginaux, limités probablement aux familles d'agriculteurs et d'éleveurs. À quelque distance de là, dans la haute montagne du Champsaur, à Champoléon, ils deviennent la règle. Là, d'immenses lignages comprenant des dizaines de branches, les Bernard, les Escallier, les Pourroy, se divisent et se distinguent constamment, jusqu’à la fin du XIXe siècle (et au-delà, sans doute), à travers des surnoms de lieux. Mais, lorsqu'une segmentation définitive survient, ce n'est pas ce nom de lieu qui est retenu, c'est un double nom de famille, plus distingué, plus noble. Nous avons ainsi les Escallier-Roux, les Escallier-Manega, les 
Escallier-Maigre (qui se divisent progressivement en Escallier-Maigre des Auberts, Escallier-Maigre du Chatelard, Escallier-Maigre des Gublas, etc.), les Escallier-Blaye, les Escallier-Cachon, les Escallier-Duron, etc. Le deuxième nom peut être apporté par une femme mais cela ne semble pas systématique. Il peut aussi se retrouver dans plusieurs familles mais dans un ordre inverse : nous avons ainsi les Serre-Besson et les Jullien-Serre. Pour les Escallier comme pour d'autres très grands groupes pris dans leur ensemble, il faut sans doute parler de clan plus que de lignage. Nous retrouvons là une organisation familiale et sociale fréquente dans les pays de montagne, que ce soit dans les Alpes françaises, italiennes ou suisses.

Une des conséquences importantes de ces divisions est de permettre des reprises d'alliances fréquentes entre les différents segments : les EscallierRoux s'unissent fréquemment aux Escallier-Duron, aux Escallier-Peyre... Ce qui n'exclue pas, par ailleurs, des mariages internes des Roux avec les Roux. Le phénomène est sans aucun doute ancien : en 1510, un Jean Jullien-Saulque aurait épousé une Florette Jullien-Baille.

La relation entre segmentation et reprise des alliances est confirmée par un exemple inverse. Les Moynier semblent avoir connu des ébauches de segmentations jusque vers le milieu du XVI e siècle. $A u X V^{e}$ siècle, nous trouvons des Moynier de la Bâtie-Vieille et, à la fin du XVI ${ }^{\mathrm{e}}$ et début du $\mathrm{XVII}^{\mathrm{e}}$ siècle, deux Moynier s'unissent respectivement à une Moynier Rambaud et à une Moynier du Lara. Mais le processus de différenciation interne semble s'être alors arrêté, et, avec lui, les mariages dans le même nom ou le nom composé ; il faudra attendre 1762 pour les voir réapparâtre.

Un problème se pose ici avec force : comment les échanges matrimoniaux entre membres de segments différents d'un même lignage étaient-ils vécus et perçus par les protagonistes eux-mêmes? Le mariage unissait-il un Escallier avec une Escallier ou plutôt un Roux avec une Duron? Quel regard les représentants extérieurs des pouvoirs ecclésiastiques et civils ont-ils porté sur des réalités aussi complexes et mouvantes? Et comment l'ont-ils exprimé au niveau de la documentation officielle (par exemple, dans les "procès " pour dispense de consanguinité ou d'affinité) qu'ils ont pu rédiger? Ont-ils transcrit les surnoms, les doubles noms avec les divisions internes qu'ils impliquaient? Ont-ils construit des sources qui, à travers une plus ou moins grande uniformisation des noms de famille, ont gommé ou respecté la réalité sociale ? La réponse varie sans doute suivant les contextes.

Ces mécanismes de segmentation et de reprise d'alliances ne sont pas l'apanage des régions de montagne. Les Cibot de Limoges (Ruchaud et al. 1993) comptent plusieurs dizaines de lignées au milieu du XVII siècle, toutes probablement issues d'un même ancêtre commun (Guillaume?) 
ayant vécu vers le milieu du XV $\mathrm{XV}^{\mathrm{e}}$ siècle. Dès la seconde génération (fin $\mathrm{XV}^{\mathrm{e}}$ siècle), deux frères, Pierre l'aîné et Jean l'aîné, donnent naissance à deux groupes totalement séparés: le premier est composé de personnes toutes inscrites, en compagnie d'un petit nombre de représentants d'autres familles avec lesquels elles s'allient régulièrement, à la corporation des bouchers de Limoges; le second est constitué par des "bourgeois et marchands de Limoges ». Dans les deux cas, la division en "lignages» advient au niveau des fils ou petit-fils des "ancêtres fondateurs", ce qui suggère un mécanisme classique de segmentation. De Pierre l'aîné sont ainsi issus les Cibot-Rascault, Cibot-Goudendaud-Le Ringaud, CibotLe Bureau, Cibot-Las Vachas ultérieurement divisés en Cibot-Jalat et Cibot-Malinvaud, tandis que de Jean l'aîné sont issus les Cibot-Cibotat et les Cibot-Pilat. Ce mécanisme de segmentation continue à fonctionner jusqu'au XVII ${ }^{e}$ siècle, chaque division s'accompagnant de l'attribution d'un nouveau surnom. Ce dernier peut finir par s'imposer sur le nom d'origine: c'est le cas des Malinvaud apparus pourtant tardivement (issus du mariage, en 1604, de Pierre Cibot et Catherine Vayvay). Une autre famille de bouchers, les Juge, a pu ainsi s'appeler, à la fin du XV et au début du XVI ${ }^{\mathrm{e}}$ siècle, Reynault dit Farne, puis ensuite Farne dit Juge et enfin Juge tout court. Du milieu du XVI ${ }^{e}$ au XVIII ${ }^{e}$ siècle, les Ringaud se fragmentent progressivement en Ringaud-Papaud, Ringaud-Pény, Ringaud-Piffre, Ringaud-La Quitterie... Et les alliances entre différents segments des Cibot comme les alliances internes à un même segment (un Ringaud avec une Ringaud) unissent des personnes portant des dénominations multiples qui sont autant d'indicateurs de chemins qui conduisent vers un ancêtre commun: en 1641, Jacques Cibot-Le Bureau-Le Petit Monsieur épouse Catherine Cibot-Ringaud-Piffre. C'est le même mécanisme de segmentation, ici généralisé, que nous avions trouvé à Manduria avec les D’Agostina et les Maiorana, à Guillestre avec les Brun, à Champoléon avec les Escallier et les Pourroy, et qui a certainement fonctionné à Verviers jusqu'à la fin du XVe-début du XVI ${ }^{\mathrm{e}}$ siècle. Il ne faut pas en déduire pour cela qu'il y a toujours eu, historiquement, évolution d'un système segmentaire à un autre non segmentaire.

L'attribution d'un surnom ne signifie pas nécessairement segmentation; celle-ci n'advient généralement que toutes les quatre ou cinq générations. Elle classe progressivement les descendances les unes par rapport aux autres, leur permettant de régler leurs échanges matrimoniaux. Tous ces «lignages" sont en effet, au moins dans une première phase, exogames. Les données concernant la fin du XVe et le XVI $\mathrm{I}^{\mathrm{e}}$ siècle sont très incomplètes mais semblent suggérer que les alliances internes aux Cibot étaient rares, 
peut-être parce que la plupart des descendances masculines se situaient alors en deçà du $4^{\text {e }}$ degré canonique : sur les 77 mariages recensés de 1475 à 1600, deux seulement, en 1565 et 1585, unissent un Cibot à une Cibot. $\mathrm{Au} \mathrm{XVII}{ }^{e}$ siècle, ces unions se multiplient, mais concernent un Goudendaud avec une Ringaud, un Bureau avec une Las Vachas..., et non un Goudendaud avec une Goudendaud. Pour la première moitié du $\mathrm{XVII}^{\mathrm{e}}$ siècle, nous avons 14 mariages entre segments différents contre un seul interne. Si nous ne prenons en considération que les surnoms, nous avons des alliances Ringaud/Goudendaud/Malinvaux/Bureau..., ce qui signifie qu'à ce niveau l'interdit de mariage dans le même nom se trouve respecté. Mais, encore une fois, nous ne savons pas comment les protagonistes percevaient ce problème. Toutes ces unions entre Cibot de segments différents respectent, dans leur très grande majorité, les interdits canoniques de consanguinité jusqu'au $4^{\text {e }}$ degré. Pour le XVII siècle, ces bouclages peuvent être contrôlés avec une assez grande précision et, comme à Manduria, ils se situent à $65 \%$ au $5^{\mathrm{e}}$ ou $6^{\mathrm{e}}$ degré, plus rarement au $7^{\mathrm{e}}$, c'est-à-dire une fois l'interdit dépassé ${ }^{17}$.

Une dernière précision: pendant toute cette première phase, les mariages de veuves et de filles uniques semblent gérés au niveau de l'ensemble des descendants, voire au niveau de la corporation des bouchers, ce qui garantit, en fin de compte, un fonctionnement parfaitement patrilinéaire de l'ensemble.

Le "décrochage " survient dans les années 1660, quand les Le Bureau, les Jalat-Malinvaud puis les Ringaud commencent à activer, de manière répétée, des mariages internes à leur propre «lignage ». Au XVIII siècle, ces derniers deviennent majoritaires (23 contre 19). Pierre Cibot, frère de Mathieu et fils cadet de Louis Cibot-Le Jalat, époux en 1604 de Catherine Vayvay, est à l'origine des Cibot-Malinvaud qui connaissent, aux XVII et XVIII ${ }^{\mathrm{e}}$ siècles, un développement considérable. Cette division interne est encore une véritable segmentation qui repositionne les nouvelles lignées descendantes et leur impose des règles précises d'endogamie/exogamie. Mais elle est la dernière. Très vite, les Malinvaud comme les autres groupes de descendance vont multiplier les mariages dans le même nom, soit dans la parenté très proche, soit, à l'opposé, dans celle très lointaine, et les

17. Au XVII siècle, sur 29 mariages internes aux Cibot, dont j’ai pu rétablir la consanguinité en lignes masculines, $9(31 \%)$ se situent aux $3^{\mathrm{e}}, 4^{\mathrm{e}}$ ou $4^{\mathrm{e}} / 5^{\mathrm{e}}$ degrés, c'est-à-dire en deçà du seuil interdit, $19(65,5 \%)$ entre les $5^{\mathrm{e}}, 6^{\mathrm{e}}$ et $6^{\mathrm{e}} / 7^{\mathrm{e}}$ et 1 seulement au $7^{\mathrm{e}}$. Deux mariages ne présentent pas de consanguinité connue. Dans la première moitié du XVIII ${ }^{e}$ siècle, la situation se modifie fortement : les mariages entre cousins au $2^{\mathrm{e}}$ ou $3^{\mathrm{e}}$ degré sont plus nombreux, mais ceux au-delà du $7^{\mathrm{e}}$ ou ne présentant pas de consanguinité connue deviennent majoritaires et cette tendance ira en s'accentuant fortement dans la seconde moitié du XVIII et au XIX siècle. 
distinctions entre lignées descendantes qui peuvent apparaître ensuite n'ont plus une fonction de classement. Le processus de segmentation cesse vers le milieu du XVII ${ }^{\mathrm{e}}$ siècle et la diffusion de la primogéniture dans les lignées principales des Cibot comme, par ailleurs, dans la plupart des classes dirigeantes, accompagne cette évolution.

Tous les exemples analysés jusqu’ici décrivent des segmentations dans les descendances patrilinéaires. Notre système européen de parenté et d'alliance peut-il se décliner également à travers des segmentations répétées dans la parenté masculine des mères? La documentation à notre disposition est limitée car il faut disposer, pour une telle étude, d'ensembles généalogiques qui permettent de replacer les femmes dans leur filiation précise. Parmi les communautés prises en considération dans notre tableau 2 en annexe, une seule, celle de Fégréac, présente des taux de bouclages dans les "lignages" des mères très nettement supérieurs à la moyenne générale : 5,07\% dans la seconde moitié du XVII ${ }^{e}$ siècle, 7,86 \% dans la première moitié du XVIII ${ }^{\text {e }}$ Le chiffre augmente encore au XIX'e, avec respectivement 9,72 et $11,62 \%$ pour la première et la seconde moitié du siècle. Si nous tenons compte du fait qu'une reprise d'alliances implique nécessairement deux mariages, cela signifie qu'approximativement entre 15 et $25 \%$ des unions s'insèrent dans des bouclages passant par les mères. Parallèlement, les mariages dans le lignage du père se situent entre 4 et $8 \%{ }^{18}$. Cette inflexion en faveur de la parenté masculine des mères nous est confirmée par l'existence d'un comportement particulier que je ne retrouve ailleurs que de manière occasionnelle et isolée: le mariage ou le remariage d'un ou plusieurs enfants, garçons ou filles, d'une même fratrie, dans la parenté masculine de leur mère ou de leur grand-mère paternelle.

Mathurin Anneix, fils d'Angélique Guiho et veuf de Jeanne Perouze, se remarie, en 1793, avec Jeanne Guiho, fille de Michel, sa cousine patrilatérale au $4^{\mathrm{e}} / 5^{\mathrm{e}}$ degré. Son frère, Yves Anneix, suit son exemple et épouse, l'année suivante et en premières noces cette fois, Marie Guiho. Une fille de ce dernier couple, Perrine Anneix, épouse, en 1845, Mathurin Guiho, fils de Jean. On voit ainsi se dessiner de véritables chaînes de bouclages à travers les femmes. Cette pratique qui continue pendant tout le XIX siècle est cependant ancienne. En 1606, Julien Anneix épouse Julienne Laille;

18. La disproportion entre ces différents comportements est probablement plus grande encore car les filiations dans les familles de Fégréac se présentent de manière relativement désarticulées, si bien qu'une partie des bouclages dans un lignage des mères nous échappe, ce qui n'est pas le cas pour les bouclages dans le lignage du père. 
son petit-fils, Georges, réplique cette alliance en s'unissant, en 1650, à Georgine Laille. Un siècle plus tard, une arrière-petite-fille de Georges, Marie, épouse Pierre Laille. D’autres personnes à la filiation incertaine occupent peut-être des places intermédiaires dans cette chaîne (une Julienne Anneix épouse, vers 1725, un Clément Laille). Chez les Bocquel, Vincent, fils de Georges, s'unit, en 1673, à Julienne Guiho. Leur fille ânée, Jeanne, s'allie, en 1691, à Mathurin Guiho, tandis qu'une autre fille, Margherite, devenue veuve de Jean Mesnager, convole en secondes noces avec Jean Guiho. Dans une lignée collatérale, Barnabé Bocquel, le seul garçon de la fratrie issue de Julien Bocquel, frère de Vincent, épouse, en 1707, Claudine Guiho. Dans ce cas, le mécanisme "normal» de réplique d'une alliance dans la collatéralité se trouve respecté. Inversement, leur fils aîné, Jean, s'allie, en 1737, à Julienne Guiho, c'est-à-dire dans le lignage de sa mère. Ils sont à l'origine d'une descendance nombreuse dans laquelle les Guiho se représentent constamment: Marie Jeanne Bocquel, petite-fille de Jean, s'unit, en 1818, à Pierre Guiho, tandis que Joseph Pierre Bocquel, autre petit-fils d'une autre branche, épouse, en 1819, Françoise Guiho. Les noces d'Anne Virginie Bocquel, arrière-petite-fille de Jean sont célébrées en 1861 avec Joseph Guiho, celles de Joseph Marie Bocquel, en 1863, avec Marguerite Marie Guiho.

Entre-temps, un neveu patrilatéral de Jean, Pierre Bocquel, s'est uni, en 1777, avec Perrine Guiho : il y a donc réplique à la fois dans la collatéralité (par rapport au mariage Jean Bocquel avec Julienne Guiho) et dans l'ascendance directe (mariage Barnabé Bocquel avec Claudine Guiho). Enfin, une fille de Pierre, Marie, épouse, en 1800, Laurent Guiho ${ }^{19}$.

Je pourrais, là encore, citer de nombreux autres exemples, non seulement à Fégréac, mais dans tous les autres villages de la région, à Guenrouët ou à Campbon.

Il conviendra de préciser ultérieurement les contextes dans lesquels de telles répliques d'alliances dans le lignage d'une mère se produisent. Cette pratique est-elle le résultat d'une évolution plus ou moins récente, dans cette région, du système de parenté et d'alliance ou doit-elle être rattachée à un passé plus ancien, éventuellement celtique ? Toute réponse tranchée semble prématurée. Je me contenterai, pour l'instant, d'insister sur le fait que de tels comportements qui supposent des «segmentations " régulières représentent le pendant exact, du côté féminin, de ceux observés, du côté masculin, chez les Cibot de Limoges.

19. Les interruptions de filiations ne permettent pas de préciser la plupart des parentés entre tous les Guiho cités. 


\section{L'Angleterre: un autre système?}

118 J'ai considéré, jusqu'à présent, des exemples pris dans des régions continentales restées catholiques. Sans entrer dans le détail de situations et de problèmes complexes, nous pouvons nous demander si la Réforme protestante - luthérienne, calviniste ou anglicane - a entrâné des modifications fondamentales dans ce système d'échange? Cela est certainement vrai sur le plan législatif: le mariage n'est plus un sacrement relevant du pouvoir ecclésiastique mais un simple contrat civil, même si souvent les Églises réformées continueront à le "gérer ". Les interdits de consanguinité et d'affinité ont été parfois fortement modifiés, certaines Églises retournant à ceux, très limités, de l'Ancien Testament, ce qui, dans les faits, aurait pu provoquer une multiplication des mariages très proches. La grande noblesse protestante saura profiter de ces dispositions pour accélérer un processus de repli endogame que les familles nobles catholiques poursuivent elles aussi, et, éventuellement, pour activer (en nombre limité), dès le XVI ${ }^{\mathrm{e}}$ $\mathrm{XVII}{ }^{\mathrm{e}}$ siècle, des échanges "incestueux " comme le sororat ou le lévirat.

Dans les classes roturières, les changements ne semblent pas avoir été considérables. La belle étude de David W. Sabean (1997) sur Neckarhausen, petit village de la Hesse (passée au luthéranisme), décrit, pour la fin du XVII ${ }^{e}$ et le début du XVIII ${ }^{e}$ siècle, des comportements marqués par des reprises d'alliances fréquentes dans la collatéralité, très semblables à ceux que nous trouvons à Manduria ou parmi les familles du Boulonnais.

Le cas anglais (j'exclue le Pays de Galles, l'Écosse et l'Irlande de cette première approche) se présente de manière plus complexe, à cause de la réforme religieuse anglicane, mais aussi parce que les comportements matrimoniaux apparaissent, dans ce cas, très différents de ceux constatés sur le continent et ce, avant même la Réforme.

Les registres paroissiaux anglais sont souvent très précoces mais d'utilisation difficile. Les indications concernant le nom des femmes, leur famille d'origine, la filiation des époux (etc.) sont souvent lacunaires. Les généalogies transmises par les contemporains ou reconstruites par les chercheurs sont nombreuses, mais présentent fréquemment de grandes difficultés d'utilisation liées à l'identification des épouses, aux ruptures fréquentes de filiations et à la méconnaissance, du fait des mouvements migratoires, du destin de nombreuses lignées collatérales. Un exemple de ces difficultés est donné par les généalogies reconstruites par Anne Mitson (1993) pour le Nottinghamshire du Sud-Ouest. 
Une première lecture rapide de ces registres paroissiaux permet toutefois de préciser un certain nombre d'éléments. À Ardingly, petit village du Sussex, un seul mariage - sur un total général de 585 - dans le même nom a été célébré entre 1558 et 1800 , celui de Gasper Wheller et Bridget Wheller, le 4 mai 1594. Il faut attendre le 20 avril 1839 pour que Peter Williams épouse Amelia Williams, puis le 16 juillet 1864 pour que de nouveau deux Williams, Thomas et Prudence, s'unissent en justes noces. Nous trouvons encore deux autres unions dans le même nom en 1895 (Cook) et 1900 (Pattenden). Comme dans la plupart des communautés que j'ai prises en considération, le XVI et le XVII siècle apparaissent quasi vides de mariages dans le même nom, tandis que le XVIII et le XIX se caractérisent par une poussée de ce type d'unions. Les proportions, toutefois, restent infimes : moins de $1 \%$.

Le petit bourg de Gerrans, en Cornouailles, présente une situation proche de celle d'Ardingly. De 1538 à 1600, on trouve un mariage dans le même nom (Laurence Sampson et Jane Sampson alias Treworva, le 08/06/1572) sur un total de 268 (0,37\%), un dans la première moitié du $\mathrm{XVII}^{\mathrm{e}}$ siècle, aucun dans la seconde moitié du XVII et la première moitié du XVIII , trois dans la seconde moitié du XVIII ${ }^{\mathrm{e}}(1,25 \%)$. Toutefois, à Gerrans, les surnoms (alias) restent très nombreux, au moins jusqu'au milieu du XVII ${ }^{\mathrm{e}}$ siècle : Morrish alias Carrow, Gerrans alias Polloghhon, John alias Pascow, etc. Certains surnoms dérivent de remariages et ne s'attachent qu'à une personne, mais d'autres semblent avoir été transmis à une descendance et, comme à Verviers, rien ne permet d'exclure que le phénomène ne fausse pas notre vision des mariages dans le même nom.

Dans le gros bourg de Horsham, de 1541 à 1635, nous ne trouvons également que peu d'unions internes. Mais, la meilleure qualité des registres qui précisent certaines filiations ou unions précédentes permet de mieux cerner les problèmes. Ainsi, le 17 février 1584, un William Michell épouse une Margaret Michell, ce qui représente certainement une véritable union interne. En revanche, en 1599, Richard Michell s'unit à une veuve, Lettice Mychell, mais, cette dernière étant indiquée sous le patronyme de son premier mari ${ }^{20}$, il n'y a pas là, au-delà même de la différence orthographique, mariage dans le même nom (Lettice est en réalité Lettice Nye). Tout au plus pouvons-nous en conclure que la femme s'est probablement remariée dans le même nom. Le cas n'est pas unique : le 22 mai 1575, "John Fiste maried to Joane Fist, widowe» (Rice 1915: 22), et le

20. Le fait est commun à la plupart des registres paroissiaux, parfois jusqu'au XIX siècle. Il représente une source possible d'erreurs dans l'évaluation des mariages internes et des remariages dans le même nom, même si son incidence est probablement faible. 
24 janvier 1555, Roger Voyce avait épousé Elysabeth, « dowghter of John Hall, now dede, \& of Elysabeth hys wife, now the wife of Thomas Hall, gent " (Ibid.: 9). Tout cela pourrait traduire une certaine tendance au lévirat. La pratique, fréquente sur le continent, de remariages suivis de l'union des enfants de premiers lits est également bien présente: le 11 octobre 1556, Thomas, fils de William Stanforde, prend pour épouse Elysabeth, fille de Thomas Chanell, «deceasyd, \& of Johan hys wyfe, late the wiffe of the seyd Wyllm. Stanforde" (Ibid.: 10).

Les données tirées de ces exemples dispersés apparaissent concordantes. Aujourd'hui, des dépouillements nombreux et facilement accessibles concernant la Cornouailles permettent d'avoir une vision plus sûre du phénomène des mariages dans le même nom. J'ai dressé, pour un certain nombre de paroisses présentant des registres couvrant toute la période de la seconde moitié du XVI è la fin du XIXe siècle (avec quelques interruptions), une statistique précise de ces unions.

\begin{tabular}{|cccccccc|}
\hline & 1 & 2 & 3 & 4 & 5 & 6 & 7 \\
$\begin{array}{l}\text { Nombre total } \\
\text { de mariages }\end{array}$ & 1929 & 2983 & 3641 & 5323 & 7342 & 11229 & 6356 \\
$\begin{array}{l}\text { Mariages dans } \\
\text { le même nom }\end{array}$ & 15 & 12 & 28 & 98 & 162 & 233 & 112 \\
Proportions & $0,77 \%$ & $0,40 \%$ & $0,76 \%$ & $1,87 \%$ & $2,20 \%$ & $2,07 \%$ & $1,76 \%$ \\
\hline
\end{tabular}

$\left(I=\right.$ seconde moitié du $X V V^{e}$ siècle $; 2=$ première moitié $d u X V \|^{e} ; 3=$ seconde moitié du XVII ; 4 = première moitié $d u X V \| l \mid ; 5=$ seconde moitié $d u X V \| I^{e} ; 6=$ première moitié $d u X I X^{e}$; 7 = seconde moitié $d u X\left(X^{\mathrm{e}}\right)$.

Cornouailles. Mariages dans le même nom (v. I550-v. 1900) ${ }^{21}$

Le nombre total de mariages ne traduit qu'imparfaitement l'évolution démographique de l'ensemble des communautés car les séries paroissiales ne sont pas toutes parfaitement continues. Ce qui importe, ce sont les chiffres globaux et les proportions de mariages dans le même nom obtenus à partir de grands nombres. Ils dénotent une situation et une évolution qui apparaît très proche de celle constatée sur le continent : pourcentages

21. Les paroisses prises en considération sont Botus Fleming, Boyton, Breage, St Breward, Calstock, Constantine, St Columb Minor, St Erth, Gerrans, St Just in Penwith, Kenwyn, St Mellion, St Michael Penkevil, Perranuthnoe, Sancreed, Sithney, Trewen, Wendron. Léchantillon comprend des paroisses côtières comme de l'intérieur, petites ou grandes [cf. www.cornwall-opc-org]. 
très faibles aux XVI ${ }^{\mathrm{e}}$ et XVII ${ }^{\mathrm{e}}$ siècles, forte poussée au XVIII ${ }^{\mathrm{e}}$, stagnation pendant la première moitié du XIX et amorce d'un déclin dans la seconde moitié du XIX siècle. Les maxima de la seconde moitié du XVIII ${ }^{e}$ ou du premier XIX ${ }^{e}$ siècle apparaissent cependant plus faibles que ceux généralement constatés sur le continent ${ }^{22}$. Toutefois, comme sur le continent, cette évolution est le reflet d'autres transformations importantes (multiplication des mariages consanguins souvent de plus en plus proches aux XVIII ${ }^{\mathrm{e}}$ et XIX ${ }^{\mathrm{e}}$ siècles, accentuation du caractère patrilinéaire des alliances) et elle se réalise à travers l'ajout successif de familles engagées dans une " politique " d'alliances dans le même nom. À Saint Just in Penwith, les Bennett, qui s'unissent entre eux une première fois en 1619, se représentent à nouveau en 1718, puis en 1796. Les Thomas arrivés en 1658 reviennent en 1663, $1710,1748,1753$, puis multiplient les mariages internes jusqu'en 1865 . Sur toute la période du milieu du XVII à la seconde moitié du XIX ${ }^{\mathrm{e}}$ siècle, près de $17 \%$ des relations de ce type (23 sur 136) sont le fait des Thomas. D'autres familles les rejoignent ensuite : les Oates, en 1689, et surtout les Williams, en 1719. À Breage, les Polglase, les Richards, les Williams se joignent progressivement aux Pearce apparus en 1656. À Sithney, les unions dans le même nom ne se présentent qu'à la fin du XVII et au début du XVIII , avec les Williams et les Pascoe. Pendant près d'un siècle et demi, un mariage interne sur cinq sera le fait de ces derniers. Toutefois, comme c'est également le cas sur le continent, dans les petites paroisses ou dans celles qui, comme Kenwyn ou Calstock, connaissent aux XVIII ${ }^{\mathrm{e}}$ et XIX siècles une croissance démographique impétueuse, la dispersion des noms est plus marquée.

L'interdit de mariage dans le même nom semble donc respecté aussi scrupuleusement en Angleterre que sur le continent et, de la même manière, les XVIII ${ }^{e}$ et XIX ${ }^{e}$ siècles y enregistrent une augmentation sensible de ce type d'alliances.

Les bouclages d'alliances dans le lignage d'une mère sont difficiles à appréhender: les filiations sont souvent incomplètes ou incertaines, le quadrillage paroissial est dense et beaucoup de communautés sont de dimensions limitées, la mobilité de la population est grande, etc. Le problème peut cependant être abordé d'une autre manière.

22. Les dépouillements effectués par B. S. Bramwell (1939) pour le Shropshire donnent des taux de mariages dans le même nom évoluant entre 1,32 et $1,74 \%$ aux XVI $I^{e}$ et XVII ${ }^{e}$ siècles. Le maximum se situe, là aussi dans la seconde moitié du XVIII ${ }^{\mathrm{e}}$ siècle, à 2,29\%. Dans les premières décennies du XIXe, on retombe déjà à $1,79 \%$. 
À Ardingly, les Paine/Payne, hommes et femmes, s'unissent, entre 1558 et la fin du XVIII e siècle (la famille disparaît ensuite), deux fois avec les Brian (1572 et 1592) et quatre fois avec les Cumber (1561, 1562, 1583 et 1784). Les 23 autres mariages restants sont noués avec des personnes de noms différents. De leur côté, les Cumber/Comber, outre les Payne, s'unissent deux fois avec les Baxshell/Baxshall (1577 et 1604). Tous les autres conjoints (37 jusqu'à la fin du XIXe siècle) proviennent de familles diverses. Les Baxshell ne renouvellent des unions, outre les Cumber, qu'avec les Wheller (1567 et 1573). À travers un certain nombre de variantes liées à la dimension démographique des communautés, à la condition sociale de certaines familles, à la mobilité géographique, les situations relevées dans les autres paroisses comme Horsham, Colyton, Gerrans, prises précédemment en considération amènent à des conclusions générales semblables: peu de groupes familiaux étoffés et très longuement présents (deux ou trois siècles) sur le territoire, peu d'échanges matrimoniaux fréquemment répétés, sur des temps longs, entre mêmes groupes alliés. La diversité, voire la dispersion des relations apparaissent comme des caractéristiques dominantes. Des cas semblables peuvent certes se rencontrer sur le continent, mais ils sont marginaux alors qu'en Angleterre ils semblent la règle. Nous pouvons tirer de tout cela deux conclusions importantes :

1) La dispersion des alliances laisse peu de probabilités pour des réplications dans les parentés masculines des mères. Toujours à Ardingly, compte tenu des autres groupes familiaux et des dates des mariages, les possibilités, du XVI è la fin du XVIII siècle, ne dépassent pas la dizaine sur un total de 585, soit moins de $2 \%$. L'« empêchement » d'alliance dans les parentés masculines des mères ne peut donc qu'être respecté.

2) De la même manière, la dispersion des alliances laisse peu de probabilités pour que les réplications dans la collatéralité, si fréquentes dans les familles des communautés rurales du continent, se réalisent. C'est à ce niveau que se situe la fracture fondamentale entre les deux rives de la Manche. La "distance» qui sépare le Boulonnais de l'Essex est incommensurablement plus grande que celle qui sépare le Boulonnais de Manduria. Est-ce à dire que le système anglais de parenté et d'alliance, qui partage avec celui du continent les mêmes interdits généraux pour les noms du père et des mères, s'organise, au-delà, suivant des principes totalement différents?

Les données disponibles ne permettent pas de résoudre le problème, mais il est possible de présenter quelques hypothèses de travail. La dispersion des alliances ne signifie pas nécessairement que ces dernières se 
nouent, en dehors de tout principe organisateur général, uniquement en fonctions de critères purement casuels et contingents. Les Payne ne s'unissent qu'une fois, en 1570, avec les Baxshell, mais ces derniers sont des alliés "traditionnels" des Cumber eux-mêmes alliés " traditionnels " des Payne. À l'exception du mariage Payne/Comber de 1764, toutes ces unions se situent entre 1561 et 1604 et peuvent donc éventuellement décrire un circuit de type Payne épouse Cumber qui épouse Baxshell qui épouse Payne, ou encore Payne épouse Baxshell qui épouse Cumber qui épouse Payne. Les filiations des différents protagonistes ne sont pas connues et nous ne savons donc pas qui est frère, sœur ou cousin de qui ; le circuit peut cependant préfigurer un mécanisme d'échanges généralisés semblable à celui que nous avons retracé dans le cas de Reggi/Puglia/Della Porta/Gennara, à Manduria. De tels schéma peuvent se reconstruire, nombreux, au niveau de toutes les paroisses anglaises. Nous pourrions donc avoir des situations dans lesquelles les échanges généralisés seraient dominants et fréquemment renouvelés, et n'excluraient pas, dans le déroulement des générations, des bouclages consanguins.

Ces relations s'accompagnent, en tout état de cause d'échanges brefs et fréquents, tels que frère-sœur avec sœur-frère ou remariage des parents suivi du mariage des enfants des premiers lits. Mais tout semble s'arrêter là; les réplications et les vastes déploiements d'alliances à travers les lignées collatérales pendant de nombreuses générations, parfois pendant des siècles, se cherchent souvent en vain. Elles ne sont toutefois pas complètement absentes.

À Myddle (Hey 1974), dans le Shropshire, nous trouvons, au XVII et début du XVIII ${ }^{\mathrm{e}}$ siècle, des Atcherley frère et sœur qui épousent des Griffiths probablement sœur et frère, une Alice Brayne qui épouse en 1668 John Eaton, puis sa nièce, Mary Brayne qui épouse, en 1716, William Eaton, une Margery Chaloner et son petit-neveu, William, qui épousent respectivement, en 1592 et 1663, un Thomas Formston et une Margaret Formston, une Ellen et une Elizabeth Hodden, tante et nièce, qui s'unissent en 1581 et 1603 à John et Owen Lloyd, une Mary Formston et sa nièce Mary mariées en 1635 et 1663 à des Chaloner. Les réplications d'alliances se font donc bien dans la collatéralité et, si nous trouvons chez les Formston deux cas de reprise dans la parenté de la mère, nous ne pouvons exclure qu'il y ait eu remariage et que les mères soient, en réalité, des belles-mères.

Le cadre paroissial masque probablement une partie des échanges. De très nombreuses études ont souligné l'importance de la mobilité de la population anglaise, mobilité qui n'entraîne pas nécessairement et toujours un relâchement ou une rupture des liens familiaux (Cressy 1986). À l'instar 
des laboureurs du Boulonnais, certaines familles peuvent entretenir des échanges sur des aires géographiques relativement vastes et ceux-ci, faute d'une documentation adéquate, risquent de nous échapper.

Toutefois, même si on retient une hypothèse haute, il ne fait guère de doute que les échanges "organisés" restent très minoritaires dans un contexte général où les relations matrimoniales font appel à des alliés toujours nouveaux et où chaque lignée semble jouer son propre jeu, indépendamment des autres. David Cressy (ibid.), après avoir recensé les différents travaux et les "contradictory views of the english kinship system " qui en résultent, n'en conclut pas moins : "Kin interaction in posse was rich, variable and wide-ranging, even in esse, in quantifiable sources such as wills, it was more likely to appear narrow and restrited » (ibid.: 69). Une perspective qui est proche de celle de Ralph A. Houlbrooke (1984) ou de Will Coster (2001), mais soulève le problème des sources et des données prises en considération. Les testaments risquent d'offrir, partout, en Angleterre comme sur le continent, une vision "courte" de la parenté et de l'alliance; de même, l'organisation de la famille en fonction de la résidence (nucléaire, élargie, multiple) ne traduit pas nécessairement des conceptions et des pratiques différentes, plus ou moins amples, des relations de parenté et d'alliance.

Avant de conclure, tournons-nous un instant vers la nouvelle Angleterre qui est en train de naître de l'autre côté de l'Atlantique.

À Cranbrook, dans le Kent, John Eddy émigre en Amérique en 1630, en compagnie de son frère, Samuel, et de ses sœurs, Anna et Abigail ${ }^{23}$. Il est l'époux d'Amy Dogget, alliance que répliquent son neveu John et sa petite-nièce Amy (avec respectivement Hepzibah Elizabeth et Joseph Dogget). Entre-temps, deux frères Eddy ont épousé deux sœurs Paddock, deux autres frères Eddy, deux sœurs Savery et deux sœurs Eddy, deux frères Mantar. Chez les Starr ${ }^{24}$, eux aussi émigrés très tôt, un premier mariage avec les Williams, au début du XVIII e siècle, est suivi par trois autres, tous dans des branches collatérales, à la fin du XVIII et au début du XIXe siècle.

À Colyton, dans le Devon, Roger Conant fait partie des premières vagues d'émigrants vers l'Amérique ${ }^{25}$. Il meurt à Beverly, en 1679. Sa fille, Mary Conant, née à Salem, prend pour époux, vers le milieu du $\mathrm{XVII}^{\mathrm{e}}$ siècle, William Dodge. Dans la première moitié du XVIII ${ }^{\mathrm{e}}$ siècle, les

23. Cf. "Généalogie B. Valcovic", sur geneanet.org.

24. Cf. "Généalogie S. Best ", sur geneanet.org.

25. Cf. "Généalogie R. Hoy ; New England Historical \& Genealogical Register, 1993 \& 1994 », sur geneanet.org. 
petits-neveux de Mary, John et Daniel Conant, s'adressent de nouveau aux Dodge pour se procurer chacun une épouse. Leur père et leur oncle, John et Nathaniel, s'étaient précédemment mariés à deux sœurs Mansfield.

À Bottesford, dans le Leicestershire, Marmaduke Morley s'unit, en 1660, à Mary Brewer. Ils mourront tous deux dans leur village, mais leur fils, Thomas, émigre, très jeune, en Amérique et y épouse, en 1681, Martha Wright, née à Sprinfield, dans le Massachussetts ${ }^{26}$. Leurs enfants, Thomas et Elizabeth Morley, s'unissent respectivement, au début du XVIII siècle, à Elizabeth et Jonathan Wickham. Une autre fille, Martha, s'allie à William Loomis. Devenu veuf, Thomas se remarie avec Mindwell Loomis. Entre-temps, une fille de ce même Thomas, Elizabeth, épouse Benjamin Loomis. Dans la seconde moitié du XVIII siècle, une autre Elizabeth, nièce de la première, s'unit à un autre Loomis, Nehemiah. Comme à Berverly et à Salem, nous ne constatons aucune reprise d'alliances dans le « lignage » du père ou dans celui des mères. Tout se joue à travers des échanges entre fratries de même niveau générationnel (en particulier avec des échanges de sœurs) ou entre lignées collatérales (oncle-

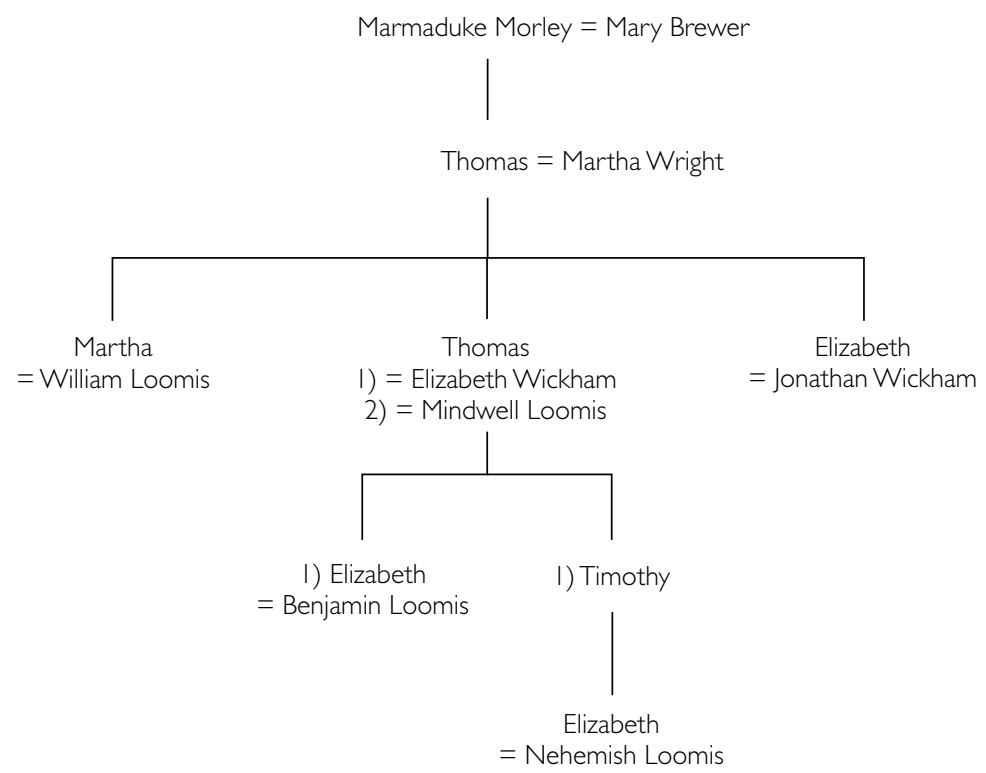

Alliances Morley-Wickham-Loomis

Bottesford (Leicestershire)/Massachussetts, $\mathrm{XVII}$-XVIII siècle

26. Cf. "Généalogie T. Billings ; Coldham, 1987-1993», sur geneanet.org. 
neveu/tante-nièce), et nous voyons bien, dans ce cas, comment les échanges brefs représentent les points de départ de constructions plus amples et structurées. Ce petit épisode répété par les Morley, au XIX siècle, de manière quasi identique avec les Cox, illustre tous les éléments fondamentaux qui caractérisent notre système européen de parenté et d'alliance.

Les Rogers présents à Constantine et dans sa région se ramifient dès le milieu du XVI ${ }^{\mathrm{e}}$ siècle en plusieurs branches difficiles à relier entre elles. La descendance de Thomas Rogers (1586-1621), qui émigre en Amérique avec le Mayflower, couvre les XVII et XVIII ${ }^{\mathrm{e}}$ siècles, et les filiations comme les noms des conjoints sont, avec quelques rares exceptions, connus (Roser 1995). Sans être systématiques, les réplications d'alliances avec d'autres familles ne sont cependant pas exceptionnelles. Un premier mariage avec les Beebe, en 1681, est suivi d'autres en 1693, 1725, 1728 et 1782. Les Fox se rencontrent en 1690, 1707 et 1714, tandis que les Powers reviennent également trois fois entre les années 1720 et 1770 . En aucun cas ces alliances ne configurent une reprise dans les descendances directes. Elles impliquent soit une fratrie (échange de sœurs ou deux frères avec deux sœurs), soit des lignées collatérales : Jerusha et Hannah Rogers épousent respectivement, en 1725 et 1728, William et Ezekiel Beebe, et une de leur nièce, Mary Rogers, fille de James, ira s'unir, en 1782, à Paul Beebe.

Tous ces exemples limités et dispersés nous permettent cependant d'avancer une conclusion fondamentale: lorsque des reprises d'alliances apparaissent, que ce soit en Angleterre ou en Amérique, elles se disposent suivant une logique et un ordre qui sont ceux-là mêmes qui se retrouvent sur le continent. Il est particulièrement remarquable de constater que, dans sa projection américaine, le système de parenté et d'alliance non seulement suit des règles identiques mais semble, en relation peut-être avec l'influence de certains courants religieux, les raviver et les renforcer. Plus que d'un système "individualiste", au sens où l'entend Alan Macfarlane (1978 et 1986), il serait pertinent, à la lumière de ces données, de parler d'un système à parenté étroite, en opposition à celui à parenté large qui prévaut dans de nombreuses régions du continent.

Le problème qui se pose, en conclusion, me paraît être le suivant : pourquoi l'Angleterre qui partage avec le continent un certain nombre de règles fondamentales concernant les échanges matrimoniaux (on ne se marie pas dans le nom de son père et de ses mères) n'a-t-elle pas, semble$\mathrm{t}$-il, construit, sur ces bases, un même système classificatoire des lignées et d'échanges matrimoniaux d'une lignée à une autre ? Peut-être l'organisation en Maisons accompagnée de primogénitures qui, sur le continent, fait place, dans la plupart des régions, à partir du XIII siècle, à des divisions 
plus ou moins égalitaires, à une réinsertion des cadets et donc à l'activation de mécanismes de type lignager, a-t-elle, appuyée sur une législation plus favorable au principe de la primogéniture et sur une grande liberté de tester, plus largement persisté en Angleterre, préservant une large autonomie des lignées associée à une forte mobilité de la population. Le rôle joué par les lignées collatérales pourrait être assumé par un autre élément, en l'occurrence, des lignées "alliées" ou "amies", ce qui déboucherait sur une organisation des alliances du type "échange généralisé ». Ce n'est qu'une explication possible. Zvi Razi (1993) insiste sur l'importance des changements survenus au XIV et dans la première moitié du $X^{e}$ siècle, liés à la diffusion et à l'affirmation de la famille nucléaire. Il convient de souligner, dans ce cas, que la prééminence du groupe domestique simple et des idéologies individualistes précède nettement le développement du capitalisme et de la société industrielle. En tout état de cause, les conclusions tirées d'études de cas anglais ne peuvent être rapportées telles quelles aux situations continentales, et vice et versa.

Le système de parenté et d'alliance européen est généralement défini comme un système cognatique avec toutes les conséquences qui en dérivent : absence de tout principe d'organisation des échanges matrimoniaux, disparition de la notion même d'échange, primauté des motivations d'ordre économique, voire des jeux de «l'amour et du hasard ». Tout cela dérive d'une lecture directe et unilatérale des interdits négatifs formalisés et légalisés qui le caractérisent, et se concilie avec une vision fortement "européocentriste» des phénomènes sociaux. Au-delà de la diversité des situations qu'elle met en lumière, notre étude du "cas » européen, qui devra, bien sûr, être étendue et précisée au niveau d'autres régions géographiques et d'autres groupes sociaux, rejoint les analyses de Françoise Héritier sur les systèmes semi-complexes et complexes d'alliance et pose le problème d'une révision des mécanismes de fonctionnement des systèmes cognatiques et des concepts sur lesquels ils se fondent.

Rome

delille@libero.it

MOTS CLÉS/KEYWORDS : parenté/kinship - système de parenté occidental/occidental kinship system - pratiques matrimoniales/matrimonial networks - bouclages consanguins - échange matrimonial/matrimonial exchange - généalogie/genealogy. 


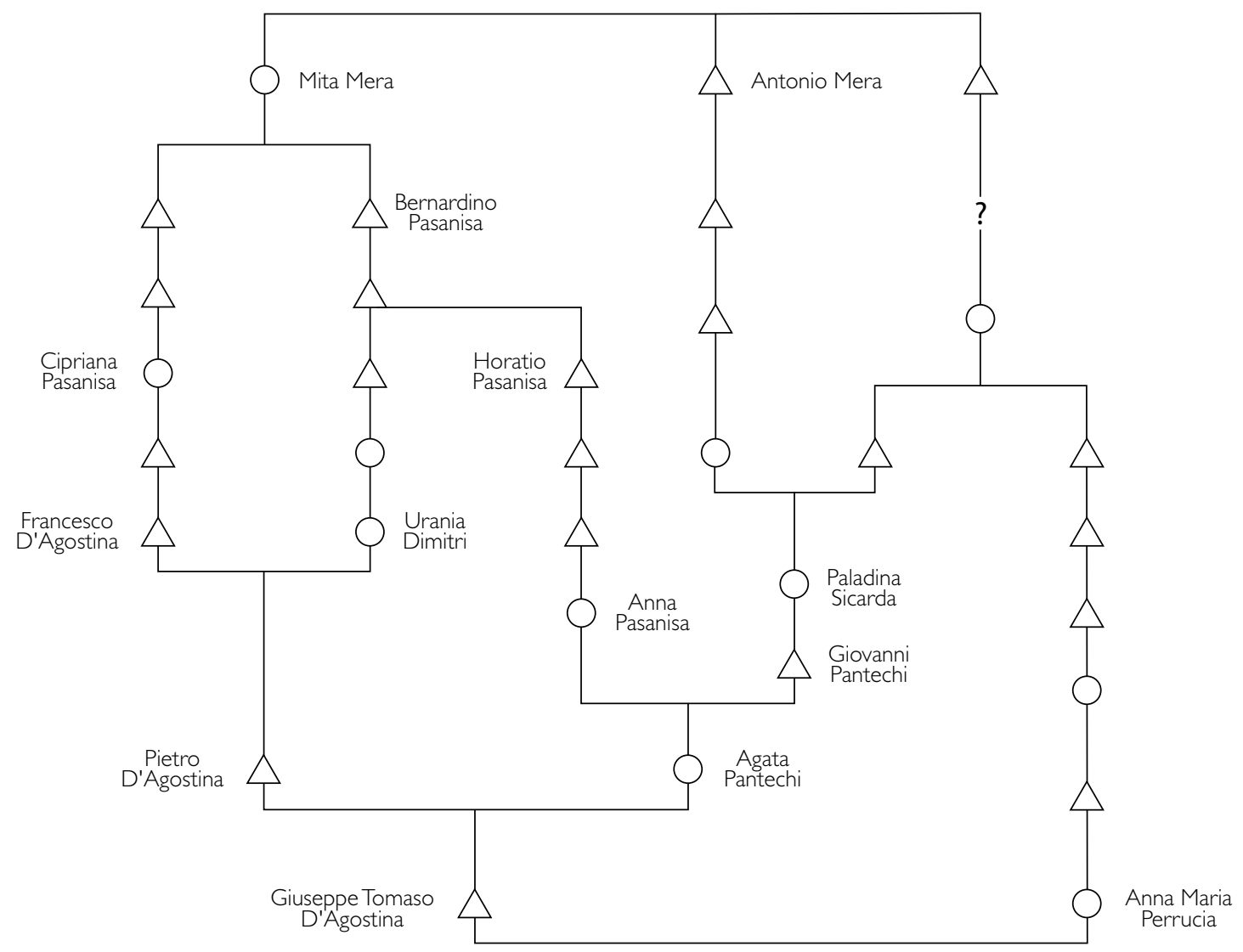

SCHÉMA I

Bouclages consanguins dans l'ascendance D'Agostina/Perruccia

Manduria, $X \mathrm{XV} \mathrm{l}^{\mathrm{e}}-\mathrm{XV} \mathrm{Il}^{\mathrm{e}}$ siècle 


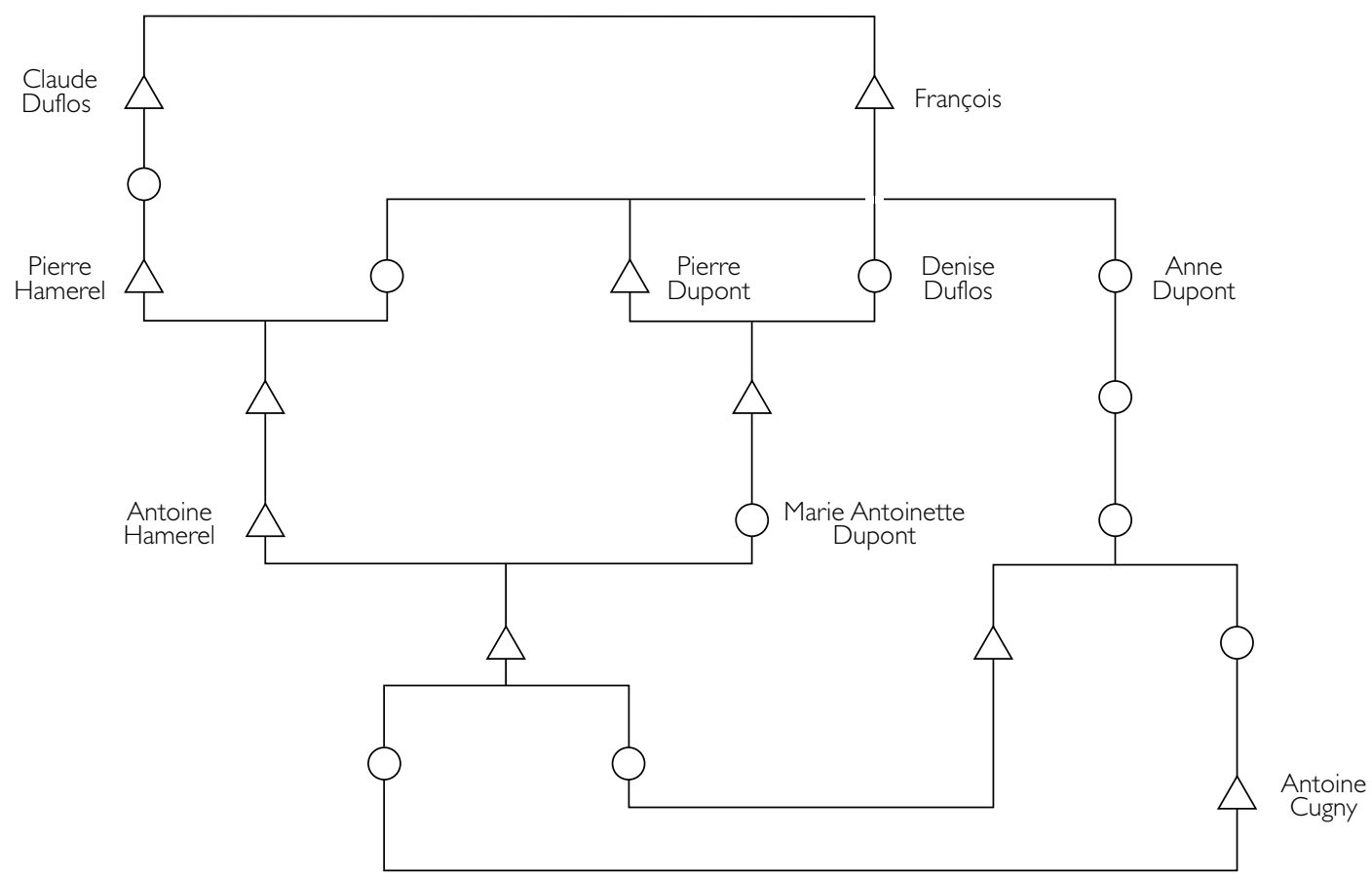

SCHÉMA 2

Bouclages consanguins dans l'ascendance Cugny/Hamerel

Boulonnais, $X \mathrm{VI} \mathrm{e}^{\mathrm{e}}-\mathrm{XVIII}{ }^{\mathrm{e}}$ siècle 
« LIGNAGES »

NOMBRE TOTAL

DE MARIAGES

$\left(X V I^{e}\right.$-début $X V I I I{ }^{e}$ siècle) (PARALLÈLES PATRILATÉRAUX)
MARIAGES DANS LA PARENTÉ MASCULINE DES MÈRES (CROISÉS MATRILATÉRAUX)

Dimitri

390

Di Donno

204

Mera

324

Micella I

295

Micella 2

337

Modea

264

Pasanisa

270

Perruccia

286

Ricchiuta

299

Agostina I

132

D'Alemma

162

184

Palmera

102

Puglia

116

Quaranta

198

141

Schiavone-Martina

Stratea I

199

Tatulla

123

Trona

135

2

6

Andrisana

62

Costa I

47

Cucci

26

Delfina

89

31

Dorante

Pantecchia

Stratea 2

51

73

Dello Vurdo

52

Maiorana I

13

Maiorana 2

3

16

Agostina 2

Agostina 3

Costa 2

Mera 2

Mera 3

Micella 3

Micella 4

Polita

Stratea 3

Urso

I I autres lignages

TOTAUX GENERAUX

4782 


\begin{tabular}{|c|c|c|c|}
\hline $\begin{array}{l}\text { REGIONS, GROUPES } \\
\text { FAMILIAUX ET PERIODES }\end{array}$ & $\begin{array}{l}\text { NOMBRE TOTAL } \\
\text { DE MARIAGES }\end{array}$ & $\begin{array}{c}\text { MARIAGES DANS LA } \\
\text { PARENTE MASCULINE } \\
\text { DU PERE }\end{array}$ & $\begin{array}{l}\text { MARIAGES DANS LA } \\
\text { PARENTE MASCULINE } \\
\text { DES MERES }\end{array}$ \\
\hline $\begin{array}{l}\text { Familles du Boulonnais } \\
\left(2^{\text {de }} \text { moitié du XVI'- }\right. \\
\text { XVIII' siècle })\end{array}$ & 2025 & $13(0,64 \%)$ & $22(1,08 \%)$ \\
\hline $\begin{array}{l}\text { Verviers, Belgique } \\
\left(2^{\text {de }} \text { moitié du XVII }\right. \\
\text { XVIIII siècle })\end{array}$ & 1485 & $8(0,53 \%)$ & $25(1,68 \%)$ \\
\hline $\begin{array}{l}\text { Guillestre, Hautes-Alpes } \\
\left(2^{\text {de }} \text { moitié du XVI }{ }^{\mathrm{e}}-\right. \\
\text { XVIII' siècle })\end{array}$ & 1487 & $70(4,70 \%)$ & $44(2,95 \%)$ \\
\hline $\begin{array}{l}\text { Fégréac, Loire-Atlantique } \\
\qquad\left(X V I I^{e}-X V I I{ }^{e} \text { siècle }\right)\end{array}$ & 2204 & $68(3,08 \%)$ & | 44 (6,53\%) \\
\hline $\begin{array}{l}\text { Les Cibot de Limoges } \\
\text { (fin XVI }{ }^{e}-X V I I I^{e} \text { siècle) }\end{array}$ & 597 & 79 (I3,23\%) & $9(1,50 \%)$ \\
\hline
\end{tabular}

TABLEAU 2

Mariages dans les parentés MASCULINES du père ET Des MĖres

EUROPE DE L'OUEST, XVI ${ }^{\mathrm{e}}$-XVIII SIĖCLE 
BIBLIOGRAPHIE

Barry, Laurent

2008 La Parenté. Paris, Gallimard.

Basile de Césarée (saint)

1961 "À Diodore [vers 373] », in Lettres.

Paris, Les Belles Lettres : II, 160.

Bourin, Monique \& Pascal Chareille, eds

1989-1995 Genèse médiévale de

l'anthroponymie moderne. Tours,

Publications de l'Université de Tours, 3 vol.

\section{Bramwell, B. S.}

1939 "Frequency of Cousin Marriages", Genealogists' Magazine 8 (6) : 305-316.

\section{Chatelain, Claire}

2008 Chronique d'une ascension sociale.

Exercice de la parenté chez de grands officiers, $X V I^{e}-X V I I^{e}$ siècle. Paris, Éd. de l'Ehess.

\section{Coldham, Peter W.}

1987-c. 1993 The Complete Book of

Emigrants. Baltimore, Genealogical Pub.

Co., 4 vol. [Computer file, 1996.]

\section{Corbet, Patrick}

2001 Autour de Burchard de Worms.

L'Église allemande et les interdits de parenté (IX'-XII siècle). Frankfurt-am-Main, Vittorio Klostermann.

\section{Corbier, Mireille}

1990 "Les comportements familiaux de l'aristocratie romaine ", in Jean Andreau \& Hinnerk Bruhns, eds, Parenté et stratégies familiales dans l'Antiquité romaine. Rome, École française de Rome : 225-249.

1994 "La Maison des Césars", in Pierre Bonte, ed., Épouser au plus proche. Inceste, prohibitions et stratégies matrimoniales autour de la Méditerranée. Paris, Éd. de l'Ehess : 243-291.

\section{Coster, Will}

2001 Family and Kinship in England, 1450-1800. London, Longman.

\section{Cressy, David}

1986 "Kinship and Kin Interaction in Early Modern England ", Past and Present 113 (1) : 38-69.

\section{Daudruy, Pierre}

1983 Familles anciennes du Boulonnais. Avec la collab. de Jean-Marie Boulanger, Henri Lorge \& Michel Parenty. Dunkerque, Westhoek, 2 vol.

1993 Familles anciennes du Boulonnais: addenda et corrigenda. Wambrechies, Groupement généalogique de la région du Nord.

\section{Delille, Gérard}

1985 Famille et propriété dans le royaume de Naples (XVe-XIXe siècle). Rome, École française de Rome / Paris, Éd. de l'Ehess. 2000 "Échanges matrimoniaux entre lignées alternées et système européen de l'alliance : une première approche ", in JeanLuc Jamard, Emmanuel Terray \& Margarita Xanthakou, eds, En substances. Textes pour Françoise Héritier. Paris, Fayard : 219-252. 2001 «Réflexions sur le "système" européen de la parenté et de l'alliance ", Annales, HSS 56 (2) : 369-380.

2003 Le Maire et le Prieur. Pouvoir central et pouvoir local en Méditerranée occidentale (XV'-XVIII siècle). Rome, École française de Rome / Paris, Éd. de l'Ehess.

2006 "Le lien fort ", in Alain Bresson et al., eds, Parenté et société dans le monde grec de l'Antiquité à l'àge moderne. Colloque international, Volos (Grèce), 19-20-21 juin 2003. Bordeaux, Ausonius : 281-296.

\section{Du Roure (baron)}

1907 Les Meyran et leurs alliances.

Généalogies provençales d'après des documents originaux. Bergerac, Castenet.

\section{Earls, John}

1971 "The Structure of Modern Andean Social Categories ", Journal of the Steward Anthropological Society 3 (1) : 69-106. 
Frémont, Henri de

1990-1993 Généalogies de familles

bourbonnaises. Courbevoie, H. de Frémont, 4 vol.

\section{Godelier, Maurice}

2004 Les Métamorphoses de la parenté.

Paris, Fayard.

Goody, Jack

1983 The Development of the Family and Marriage in Europe. Cambridge-New York, Cambridge University Press.

1990 The Oriental, the Ancient and the Primitive. Systems of Marriage and the Family in the Pre-Industrial Societies of Eurasia. Cambridge-New York, Cambridge University Press.

\section{Guerreau-Jalabert, Anita}

1996 «Prohibitions canoniques et stratégies matrimoniales dans l'aristocratie médiévale de la France du Nord ", in Pierre Bonte, ed., Epouser au plus proche. Inceste, prohibitions et stratégies matrimoniales autour de la Méditerranée. Paris, Éd. de l'Ehess : 293-321.

\section{Hamon, Philippe}

1999 Messieurs des finances. Les Grands Officiers de finance dans la France de la Renaissance. Paris, Comité pour l'histoire économique et financière de la France.

\section{Hanquet, Pierre}

1957 «Familles vierviétoises. Première série ", in Archives verviétoises VI. Verviers, Impr. Leens.

\section{Héritier, Françoise}

1981 L'Exercice de la parenté. Paris, Gallimard-Le Seuil.

1994 Les Deux Sours et leur mère. Anthropologie de l'inceste. Paris, Odile Jacob.

\section{Hey, David G.}

1974 An English Rural Community. Myddle Under the Tudors and Stuarts.

Leicester, Leicester University Press.
Houlbrooke, Ralph A.

1984 The English Family. London, Longman.

\section{Laiou, Angeliki E.}

1992 Mariage, amour et parenté à

Byzance aux XI'-XIII siècles. Paris,

De Boccard ( $"$ Travaux et mémoires du

Centre de recherche d'histoire et civilisation de Byzance »).

Le Pas de Sécheval (chevalier)

1990 "Généalogies vierviétoises ", in

Bulletin des archives vierviétoises $18: 1988$ -

1989. Verviers, Impr. Leens.

\section{Lett, Didier}

2000 Famille et parenté dans l'Occident médiéval, $V^{e}-X V^{e}$ siècle. Paris, Hachette.

\section{Macfarlane, Alan}

1978 The Origins of English Individualism. The Family, Property and Social Transition.

Oxford, Blackwell.

1986 Marriage and Love in England.

Modes of Reproduction, 1300-1840.

Oxford-New York, Blackwell.

Merzario, Raul

1981 Il Paese stretto. Strategie matrimoniali nella diocesi di Como, secoli XVI-XVIII.

Torino, G. Einaudi.

\section{Mitson, Anne}

1993 "The Significance of Kinship

Networks in the Seventeenth Century:

South-West Nottinghamshire", in Charles Phythian-Adams, ed., Societies, Cultures and Kinship, 1580-1850. Cultural Provinces and English Local History. Leicester, Leicester University Press / New York, Distrib. by St. Martin's Press : 24-76.

Moreau, Philippe

2002 Incestus et prohibitae nuptiae. Conception romaine de l'inceste et histoire des prohibitions matrimoniales pour cause de parenté dans la Rome antique. Paris, Les Belles Lettres. 
Pitsakis, Constantin G.

2006 «Parenté en dehors de la parenté :

formes de parenté d'origine extra-législative en droit byzantin et post-byzantin ", in Alain Bresson et al., eds, Parenté et société dans le monde grec de l'Antiquité à l'âge moderne. Colloque international, Volos (Grèce), 19-20-21 juin 2003. Bordeaux, Ausonius : 297-325.

Plouy, Jean

1965 "La maison de Goër de Herve", in Archives vierviétoises VIII. Verviers, Impr. Leens.

\section{Razi, Zvi}

1993 "The Myth of the Immutable English Family", Past and Present $140: 3-44$.

\section{Rheubottom, David}

2000 Age, Marriage and Politics in Fifteenth-Century Ragusa. Oxford-New York, Oxford University Press.

Rice, Robert Garraway, ed.

1915 The Parish Register of Horsham in the County of Sussex, 1541-1635.

London, Hughes \& Clarke («Sussex Record Society" 21).

\section{Roser, Susan E.}

1995 [1989] Mayflower Increasings.

Baltimore, Genealogical Pub. Co.

Ruchaud, Jean-Louis et al.

1993 Généalogies limousines et marchoises, 6. Mayenne, Éd. régionales de l'Ouest.

\section{Sabean, David Warren}

1997 Kinship in Neckarhausen (17001870). Cambridge-New York, Cambridge University Press.

\section{Segalen, Martine}

1985 Quinze Générations de Bas-Bretons. Parenté et société dans le Pays bigouden Sud, 1720-1980. Paris, Presses universitaires de France.

\section{Syme, Ronald}

1986 The Augustan Aristocracy. Oxford, Clarendon Press / New York, Oxford University Press.

\section{Tables de Fégréac}

2006 Fégréac. Tables des mariages, 1570 1905. Liste patronymique et filiative. Tables des veuvages. Liste des épouses. $3^{\mathrm{e}}$ version actualisée. Fégréac, Mémoire vivante.

\section{Tables de Guenrouët}

s. d. Guenrouët. Tables des mariages, 1 : 1565-1802; 2 : 1802-1899.

Tassin, Guy

2007 Qui épouser et comment? Alliances récurrentes à Haveluy de 1701 à 1870 .

Paris, L'Harmattan.

Veyne, Paul

1978 «La famille et l'amour sous le HautEmpire romain ", Annales, ESC 33 (1): 35-63.

Wolff, Daniel

2007 Les Familles de Jezainville, 1608-

1906. Pont-à-Mousson, Cercle généalogique de Blénod-lès-Pont-à-Mousson.

\section{Xhayet, Geneviève}

1997 Réseaux de pouvoir et solidarités de parti à Liège au Moyen Âge, 1250-1468. Liège, Bibliothèque de la Faculté de philosophie et lettres de l'Université de Liège. 
Gérard Delille, Parenté et alliance en Europe occidentale: un essai d'interprétation générale.

- L'affirmation d'un système onomastique strictement patrilinéaire et la disparition des phénomènes de segmentation entraînent, à partir des derniers siècles du Moyen Âge et jusqu'aux premières décennies du XVIII siècle, une nouvelle définition des groupes de parenté et activent des règles nouvelles d'échanges matrimoniaux. Aux interdits canoniques de l'Église s'ajoutent, pour Ego, des interdits dans la parenté masculine de son père et dans les parentés masculines des mères de sa lignée ascendante directe. Les groupes de descendance masculins se trouvent ainsi classés en "épousables " et "non épousables». Il résulte de ces règles qu'une lignée directe doit constamment renouveler ses alliances mais que ces dernières peuvent aussi être reprises par les lignées collatérales. Structurellement, les échanges ne peuvent s'organiser qu'au-delà du troisième degré canonique et les cycles et les bouclages consanguins doivent nécessairement inclure deux femmes. Lorsque les données sont suffisamment précises pour en permettre l'étude, les bouclages apparaissent systématiques et s'encastrent les uns dans les autres, assurant la cohésion et la continuité du système. Les mêmes règles fondamentales se retrouvent en Angleterre mais le renouvellement des alliances dans les lignées collatérales et les bouclages consanguins semble, dès le XVI siècle, très limité ou résiduel.
Gérard Delille, Kinship And Alliance in Western last centuries in the Middle Ages till the first decades of the $18^{\text {th }}$ century, the prevalence of a purely patrilineal onomastics and the ending of segmentation-related phenomena led to a new definition of kin groups and new rules for matrimonial exchanges. In addition to the Catholic Church's canonical prohibitions, Ego came to be subject to prohibitions both through his father's masculine kin group and through the masculine kinship bonds of mothers in direct line. Masculine descent groups were thus classified as "marriageable» or not. As a consequence of these rules, a direct line of descent had to constantly renew its marital alliances, but the latter could also be taken back by collateral lines. From a structural viewpoint, exchanges could only be organized beyond the third canonic degree of kinship, and the consanguineous loops and cycles in this process had to include two women. When the data are adequate and accurate enough to be studied, these loops turn out to be systematic. They are embedded in each other, thus ensuring the system's cohesion and continuity. The same fundamental rules existed in England, but the renewal of matrimonial alliances in the collateral lines and the consanguineous loops had apparently become very limited or even residual by the $16^{\text {th }}$ century. 